\title{
dh2loop 1.0: an open-source python library for automated processing and classification of geological logs
}

\author{
Ranee Joshi ${ }^{1,2}$, Kavitha Madaiah ${ }^{1,2}$, Mark Jessel1 ${ }^{1,2}$, Mark Lindsay ${ }^{1,2}$ and Guillaume Pirot ${ }^{1,2}$ \\ ${ }^{1}$ Centre of Exploration Targeting, School of Earth Sciences, University of Western Australia, 35 Stirling Highway, Crawley \\ 56009 Western Australia \\ ${ }^{2}$ Mineral Exploration Cooperative Research Centre (MinEx CRC), School of Earth Sciences, University of Western Australia, \\ 35 Stirling Highway, Crawley 6009 Western Australia
}

Correspondence to: Ranee Joshi (ranee.joshi@research.uwa.edu.au)

10 Abstract. Exploration and mining companies rely on geological drill core logs to target and obtain initial information on geology of the area to build models for prospectivity mapping or mine planning. A huge amount of legacy drilling data is available in geological survey but cannot be used directly as it is compiled and recorded in an unstructured textural form and using different formats depending on the database structure, company, logging geologist, investigation method, investigated materials and/or drilling campaign. It is subjective and plagued with uncertainty as it is likely to have been conducted by tens

15 to hundreds geologists, all of whom would have their own personal biases. However, this is valuable information that adds value to geoscientific data for research and exploration, specifically in efficiently targeting sustainable new discoveries and providing better shallow subsurface constraints for 3D geological models.

dh2loop (https://github.com/Loop3D/dh2loop) is an open-source python library that provides the functionality to extract and standardize geologic drill hole data and export it into readily importable interval tables (collar, survey, lithology). In this contribution, we extract, process and classify lithological logs from the Geological Survey of Western Australia Mineral Exploration Reports Database in the Yalgoo-Singleton Greenstone Belt (YSGB) region. For this study case, the extraction rate for collar, survey and lithology data is respectively $93 \%, 865$ and $34 \%$. It also addresses the subjective nature and variability of nomenclature of lithological descriptions within and across different drilling campaigns by using thesauri and fuzzy string matching. $86 \%$ of the extracted lithology data is successfully matched to lithologies in the thesauri. Since this process can be tedious, we attempted to test the string matching with the comments, which resulted to a matching rate of $16 \%(7,870$ successfully matched records out of 47,823 records). The standardized lithological data is then classified into multi-level groupings that can be used to systematically upscale and downscale drill hole data inputs for multiscale 3D geological modelling. dh2loop formats legacy data bridging the gap between utilization and maximization of legacy drill hole data and drill hole analysis functionalities available in existing python libraries (lasio, welly, striplog). 


\section{Introduction}

Drilling is the process of penetrating through the ground and extracting rocks from various depths beneath the surface for confirming the geology beneath and/or providing samples for chemical analysis. As it penetrates the ground it forms drill holes from which drill core is collected. The location of where drilling starts is referred to as the collar. As the drilling progresses, survey orientation measurements are taken to be able to convert the specific depths to exact coordinate locations of the drill core being retrieved. In a hard rock setting, geological drill core logging is the process whereby the recovered drill core sample is systematically studied to determine the lithology, mineralisation, structures, and alteration zones of a potential mineral deposit. It is usually performed by geologists who classify a rock unit into a code, based on one or multiple properties such as rock type, alteration intensity and mineralisation content. Exploration and mining companies rely on the diverse geoscientific information obtained by drill core logging techniques to target and to build models for prospectivity mapping or mine planning. This work focuses on lithological logs which is the component of a geological log that refers to the geological information on the dominant rock type in a specific downhole interval. Inevitably, lithological drill core logging is subjective and plagued with uncertainty, particularly as it is likely to have been conducted by ten to hundred geologists, all of whom would have their own personal biases (Lark et al., 2014). Furthermore, it can be difficult to recognize lithology with confidence and to establish subtle variations or boundaries in apparently homogeneous sequences.

With the advent of the digital age, semi-automated drill core logging techniques such as X-Ray Diffraction (XRD), X-Ray Fluorescence spectrometry (XRF) and Hyperspectral (HS) imaging have provided higher detail of data collection and even

50 detection of other properties such as conductivity, volumetric magnetic susceptibility, density using gamma-ray attenuation, and chemical elements during logging (Zhou et al., 2003; Rothwell and Rack, 2006;Ross et al., 2013). This has prompted a shift towards using numerical data rather than depending on traditional geological drill core logging procedures (Culshaw, 2005). Multiple methods have been recently applied to geological drill core logging such as wavelet transform analysis or data mosaic (Arabjamaloei et al., 2011;Hill et al., 2020;Le Vaillant et al., 2017;Hill et al., 2015), artificial neural network model

55 (Lindsay, 2019; Zhou et al., 2019; Emelyanova et al., 2017) and inversion (Zhu et al., 2019). Relying solely on these semiautomatic methods comes with drawbacks as it excludes some of the subjective interpretations that cannot be replaced. Furthermore, a rich amount of legacy data was collected in the traditional drill core logging method and disregarding this information limits the dataset.

60 Legacy data are information collected, compiled and/or stored in the past into many different old or obsolete formats or systems, such as handwritten records, aperture cards, floppy disks, microfiche, transparencies, magnetic tapes and/or newspaper clippings making it difficult to access and/or process (Smith et al., 2015). In geoscience, these are currently scattered amongst unpublished company reports, departmental reports, publications, petrographic reports, printed plans and maps, aerial photographs, field notebooks, sample ticket books, drill core samples, tenement information and geospatial data providing a

65 major impediment to their efficient use. This includes geological drill core logs that are the outcome of most expensive part of most mineral exploration campaigns: drilling. This is valuable information source and key assets that can be used to add value to geoscientific data for research and exploration; design mapping programs and research questions of interest; more efficiently target remapping and sustainable new discoveries; and provide customers with all existing information at the start of the remapping program. It should not be abandoned for it may have lower intrinsic quality than observations made with more

70 modern equipment, its recovery and translation to a digital format is too tedious. Elizabeth Griffin (2015) argues that there is no distinction in principle between legacy data and 'new' data, as all of it is data. The intention of recovering legacy data is to a) upcycle information with integration into modern datasets, b) use salvaged data for new scientific applications and c) allow reuse of that information into utility downstream applications (Vearncombe et al., 2017). Furthermore, extracting 
information from legacy datasets is high and relatively low-risk as geoscientific insight is added to a project for little or no cost compared to those of drilling (Vearncombe et al., 2016).

The primary challenge in dealing with geological legacy datasets is a large amount of important data, information and knowledge are recorded in an unstructured textural form, such as host rock, alteration types, geological setting, ore-controlled factors, geochemical and geophysical anomaly patterns, and location (Wang and Ma, 2019). Moreover, the geological drill core logging forms and formats vary depending on the company, logging geologist, investigation method, investigated materials and/or drilling campaign. Natural language processing (NLP) also known as computational linguistics has been used for information extraction, text classification and automatic text summarization. NLP relies on data-driven computation involving statistics, probability, machine learning and "deep learning" (Otter et al., 2020). NLP applications on legacy data have been demonstrated in the fields of taxonomy (Rivera-Quiroz and Miller, 2019), biomedicine (Liu et al., 2011) and legal services (Jallan et al., 2019). Qiu et al. (2020) proposed an ontology-based methodology to support automated classification of geological reports using word embeddings, geoscience dictionary matching and bidirectional long short-term memory model (Dic-Att-BiLSTM) that assists in identifying the difference in relevance from a report. Padarian and Fuentes (2019) also introduced the use of domain-specific word embeddings $(\mathrm{GeoVec})$ which was used to automate and reduce subjectivity of geological mapping of drill hole descriptions (Fuentes et al., 2020).

90

Similarity matching has many applications in natural language processing as it is one of the best techniques for improving retrieval effectiveness (Park et al., 2005). The use of text similarity is beneficial for text categorization (Liu and Guo, 2005) and text summarization (Erkan and Radev, 2004;Lin and Hovy, 2003). Fuzzy string matching, also known as approximate string matching, is the process of finding strings that approximately match a given pattern (Cohen, 2011; Gonzalez et al., 2017).

It has been used in language syntax checker, spell-checking, DNA analysis and detection, spam detection, sport and concert event ticket search (Higgins and Mehta, 2018), text re-use detection (Recasens et al., 2013) and clinical trials (Kumari et al., 2020).

Most of the python libraries available have been built to process extracted and standardized drill hole data. The most common of these are: lasio (https://asio.readthedocs.io/en/latest/) which deals with reading and writing Log ASCII Standard (LAS) files, a drill hole format commonly used in the oil and gas industry, welly (https://github.com/agile-geoscience/welly) which deals with loading, processing, and analysis of drill holes and striplog (https://github.com/agile-geoscience/striplog) which digitizes, visualizes and archives stratigraphic and lithological data. Striplog (Hall and Keppie, 2016) also parses natural language 'descriptions', converting them into structured data via an arbitrary lexicon which allows further querying and analysis

105 on drill hole data. The main limitations of these existing libraries, with respect to legacy data in the mining sector is that they assume that the data is already standardized and pre-processed.

dh2loop provides the functionality to extract and standardize geologic drill hole data and export it into readily importable interval tables (collar, survey, lithology). It addresses the subjective nature and variability of nomenclature of lithological 110 descriptions within and across different drilling campaigns by integrating published dictionaries, glossaries and/or thesauri that were built to improve resolution of poorly defined or highly subjective use of terminology and idiosyncratic logging methods. It is however important to highlight that verifying the accuracy and/or correctness of the geological logs being standardized is outside the scope of this tool, thus we assume logging has been conducted to the best of the geologist's ability.

115 Furthermore, it classifies lithological data into multi-level groupings that can be used to systematically upscale and downscale drill hole data inputs in multiscale 3D geological model. It also provides drill hole desurveying (computes the geometry of a 
drillhole in three-dimensional space) and log correlation functions so that the results can be plotted in 3D and analysed against each other. It also links the gap between utilization and maximization of legacy drill hole data and the drill hole analysis functionalities available in existing python libraries.

\subsection{Conventions}

This paper involves multiple python libraries, database tables and fields. For clarity, the following conventions are used for this paper:

1. Python libraries are written in italics: dh2loop

2. Python functions are written in italics followed by an open and close parenthesis: token_set_ratio()

3. Database tables are written in Lucinda Console Italics: dhgeo 7ogy

4. Database table fields are written in Lucinda Console: Co11 arID

\subsection{Dependencies}

dh2loop stands for drill hole data extracted into a 3D modelling input format, compatible with/for the Loop platform. It is a drill hole processing tool that integrates published dictionaries, glossaries and/or thesauri to and improve standardize highly subjective use of terminology and idiosyncratic logging methods and classify lithological logs. It primarily depends on a number of external open-source libraries:

1. fuzzywuzzy (https://github.com/seatgeek/fuzzywuzzy) which uses fuzzy logic for string matching (Cohen, 2011)

2. pandas (https://pandas.pydata.org/) for data analysis and manipulation (McKinney, 2011)

3. psycopg2 (https://pypi.org/project/psycopg2/), a PostgreSQL database adapter for python (Gregorio and Varrazzo, 2018)

4. numpy (https://github.com/numpy/numpy)

5. nltk (https://github.com/nltk/nltk ), the Natural Language Toolkit is a suite of open source Python modules, data sets, and tutorials supporting research and development in Natural Language Processing (Loper and Bird, 2002).

6. pyproj (https://github.com/pyproj4/pyproj), python interface to PROJ (cartographic projections and coordinate transformations library)

Code describing basic drill hole operations, such as desurveying (process of translating collar (location) and survey data (azimuth, dip, length) of drill holes into XYZ coordinates in order to define its 3D geometry of the non-vertical borehole), was heavily inspired from $p y G S L I B$ drill hole module (Martínez-Vargas, 2016). pyGSLIB (https://github.com/opengeostat/pygslib) is an open-source python package to perform mineral resource estimations. The pyGSLIB drillhole module handles drill hole data, desurveying interval tables and other drill hole related processes. The module was re-written into python to be make it more compact with less dependencies and tailor it to the data extraction output.

\subsection{Data Source}

The Geological Survey of Western Australia Mineral Exploration Reports Database contains open-file reports submitted as a compliance to the Sunset Clause, Regulation 96(4) of the Western Australia legislation Mining Regulations 1981. These reports contain valuable exploration information in hardcopy (1957-2000), hardcopy and digital format (2000-2007) and digital format (2000-present) (Riganti et al., 2015). The minimum contents of a drilling report comprise a collar file which describe the geographic coordinates of the collar location (Fig. 1). Additional files may be included, such as a survey file describing the depth, azimuth and dip measurements for the drilling path; assays; downhole geology and property surveys (e.g. downhole geochemistry, petrophysics) may also be available depending on the company's submission (Riganti et al., 2015). The data in 

the Mineral Drillhole Database) curated by the GSWA that allows easy retrieval and spatial querying. For simplicity, we will refer to this database as the WAMEX database in this text.

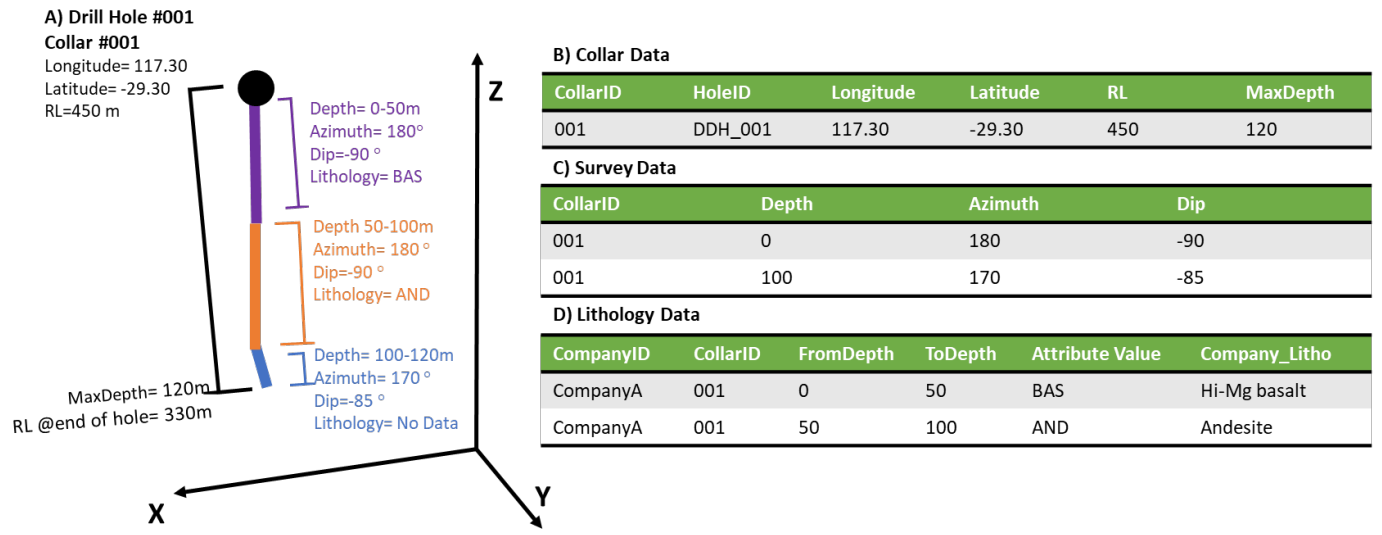

160 Figure 1. Simplified example of a drill hole (1.A) and its corresponding interval tables collar (1.B), survey (1.C) and lithology (1.D). The black circle denotes the collar location of the drill hole which is obtained from a collar table (1.B). The purple line represents the first downhole interval taking its deviation data from the survey table (1.C) and the lithology information from the lithology table (1.D). The same applies for the second interval (orange line) and third interval (blue line). The orange line follows the same trajectory as the first interval as it uses the same entry in the survey table (1.C). The blue line has no lithology data as this information is not present in the lithology table (1.D). The MaxDepth denotes the total drill length (1.B).

Each drill hole in the WAMEX database is identified by its surface coordinates and a unique ID (Co11 arID) in the co7 7ar table. The drill hole 3D geometry is described in the survey tables (dhsurvey, dhsurveyattr). The properties logged are described in pair of tables such as dhgeology, dhgeologyattr. The WAMEX schema is linked by a main table, co7 7ar, which assigns a primary key (Co11 arID) for each drill hole in Western Australia and corresponding geographic location (Fig. 2). co77ar has a one-to-many relationship with another table, co77arattr, to store other attributes that describe each unique drill hole, such as maximum depth and elevation. The deviation of the drill hole is stored in a table, dhsurvey, with a primary key (DHSurveyID) that refers to each unique depth of a drill hole. This primary key has a manyto-one relationship with collar, as there are multiple depth measurements for each drill hole. Furthermore, dhsurvey also has a one-to-many relationship with table dhsurveyattr, which stores additional attribute information regarding survey, such as azimuth and dip readings. This similar relationship is maintained with interval tables, except that the primary key (e.g.DHGeologyID) is used to refer a unique downhole interval rather than a depth measurement. For lithological information, we refer to tables: dhgeology and dhgeologyattr. dhgeologyattr which contain information such as rock names and free text comments while dhgeology provides information to which hole and interval depth that data refers

180 to. This information can be joined and extracted through SQL (Structured Query Language) queries. Other interval tables available in the database refer to typical logs and downhole surveys: alteration, events, geochemistry geophysics, geotech, hyperspectral, magnetic susceptibility, mineralogy, recovery, regolith, specific gravity, structure, veining, water level and weathering information. 


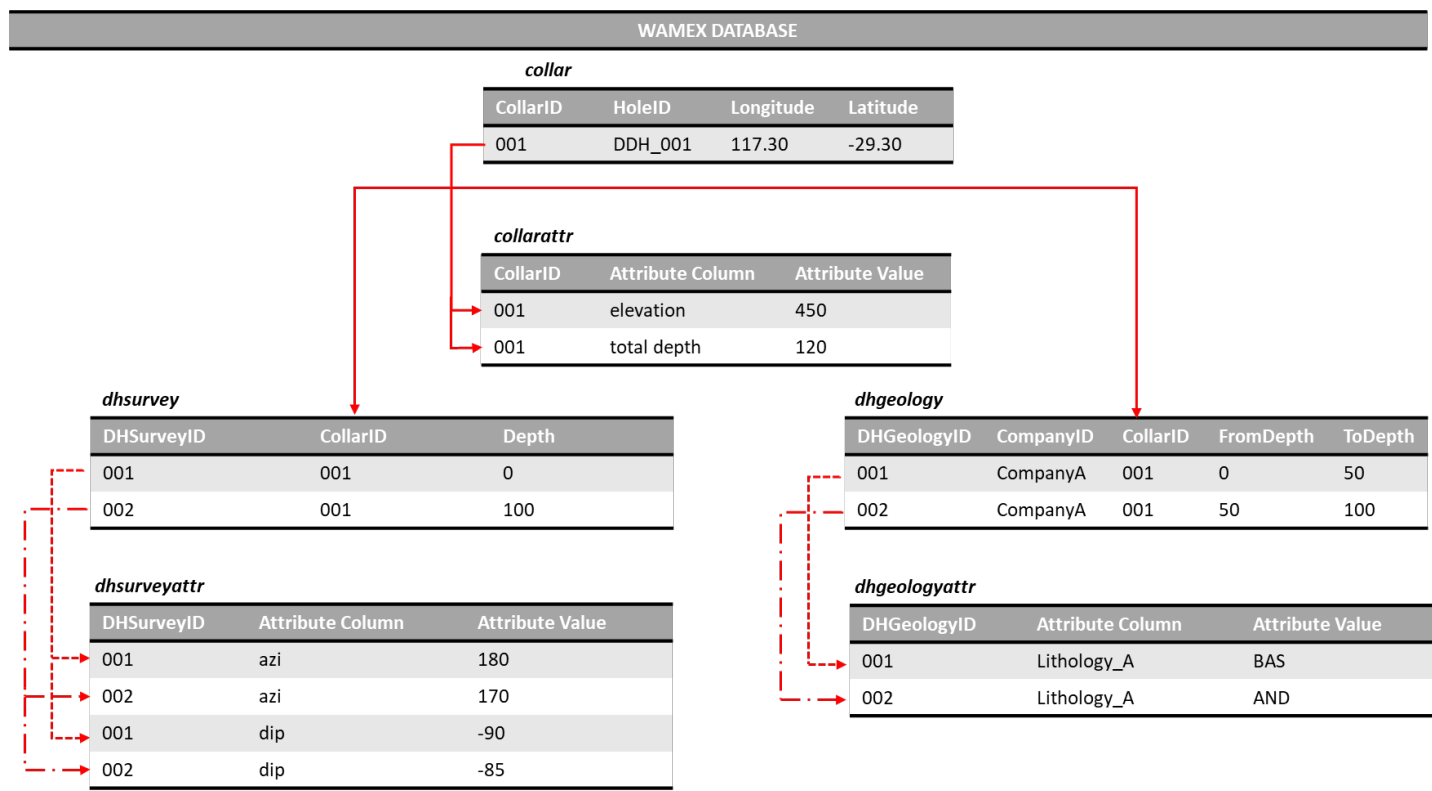

185 Figure 2. Simplified WAMEX database schema showing the one-to-many relationship between the col7ar table and the co77arattr table (red solid line). It also shows the relationship between the collar table and the other interval tables such as dhsurvey, dhsurveyattr, dhgeology, dhgeologyattr. The example show the relationship between tables for the first (red dashed line) and second interval (red dashed-dot line).

It contains more than 50 years worth of mineral exploration drill hole data with more than 2.05 million drill holes, imported from over 1,514 companies. Each drill hole is identified by its surface coordinates and its unique ID (Co11 arID). The drill hole 3D geometry is described in the survey tables (dhsurvey, dhsurveyattr). However, it is important to emphasize that the drill hole data is of variable quality and reliability and no validation has been done. The amendments and reformatting necessary to be able to extract and utilize data from the WAMEX database is part of the functionalities provided by dh2loop.

\subsection{Study Area}

195 In this paper, we demonstrate the application of dh2loop to data from the Yalgoo-Singleton greenstone belt (YSGB) (Fig. 2), a geologically complex, largely heterogeneous and highly mineralized arcuate granite-greenstone terrane, in the western Youanmi Terrane, Yilgarn Craton in Western Australia (Anand and Butt, 2010). The YSGB has good range of different lithologies in the area. Igneous rocks occur as extensive granitoid intrusions that occurred between 2700 and $2630 \mathrm{Ma}$ (Myers, 1993), as well as ultramafic mafic volcanic rocks formed as extensive submarine lavas and local centres of felsic and mafic

200 volcanic rocks. Some layered gabbroic sills intruding the greenstone are also observed. Sedimentary rocks formed in broad basins during tectonic and volcanic quiescence consist of mostly banded iron formation (BIF) and felsic volcanoclastic rocks. The greenstone belt is metamorphosed to greenschist facies (Barley et al., 2008). The area is also covered by deeply weathered regolith profiles which both conceals mineral deposits hosted by the underlying bedrock and contains signatures of mineralisation that are distal signatures of possible economically significant deposits (Cockbain, 2002). Furthermore, the

205 YSGB is a major target for exploration as it has considerable resources of gold, nickel, bauxite, as well as lesser amounts of a wide range of other commodities (Cockbain, 2002). It hosts multiple mineral deposits ranging from volcanogenic massive sulphide (Golden Grove, Gossan Hill), orogenic gold (Mt. Magnet), banded iron formations (Mount Gibson, Karara, Extension Hill). The geological complexity and relevance to mineral exploration makes the YSGB a reasonable and sensible area to test the dh2loop thesauri, matching and upscaling. 


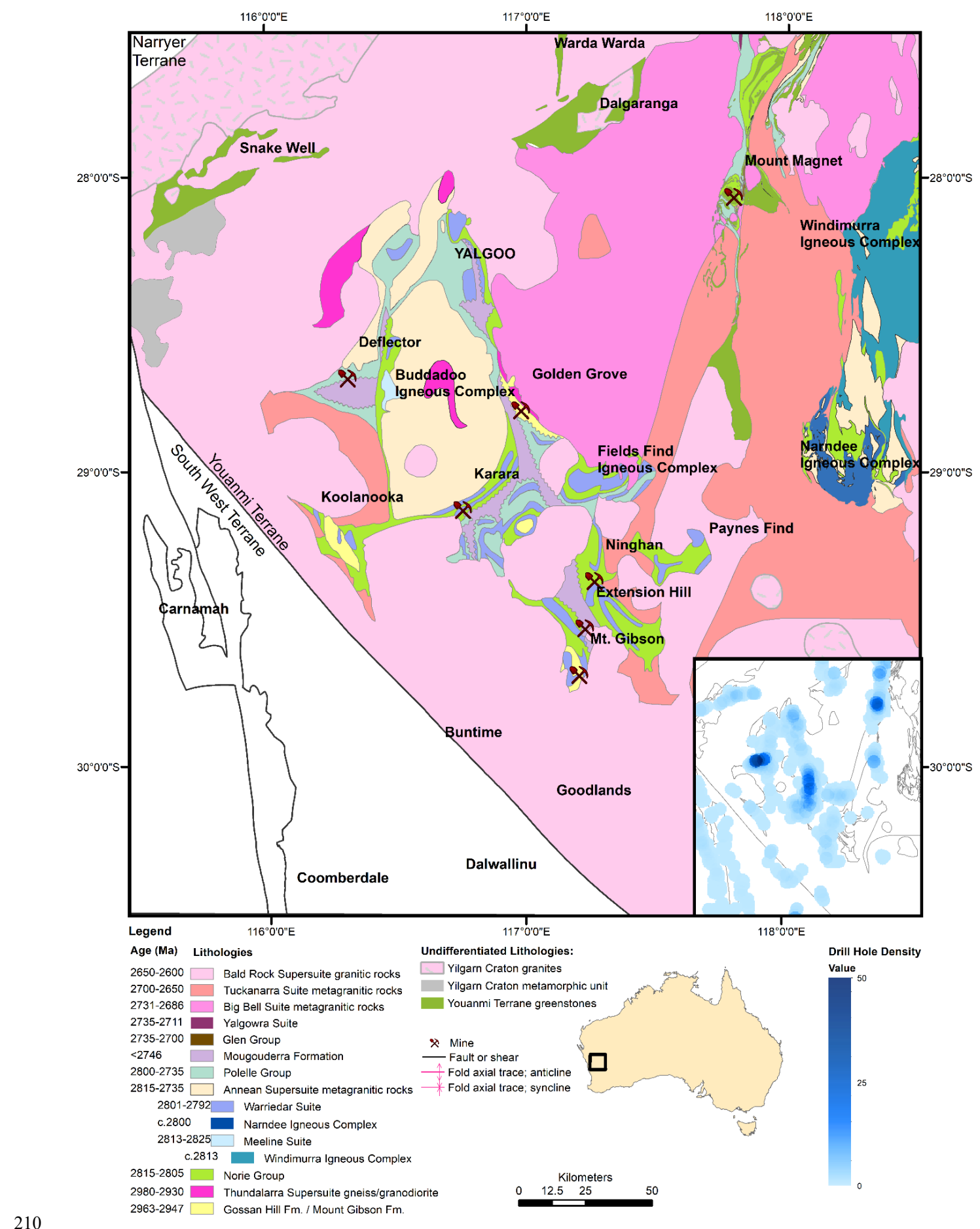

Figure 3. The map shows the Yalgoo-Singleton greenstone belt highlighting the different mines and prospects in the area. The inset map shows the heterogeneous distribution and drill hole density from the legacy data available from the WAMEX database. 


\subsection{Thesauri}

Since most exploration companies have their own nomenclature and systems, which could also change between drilling campaigns, it is necessary to build thesauri: dictionaries that list equivalent and related nomenclature (or synonyms) for different attribute names and values. These thesauri are stored as additional tables in the database. For example, if we are interested in the major lithology in a specific interval, this information can be tabulated as "Major Rock Type", "Lithology_A" or "Main_Geology_Unit" depending on the drill core logging system used. The resulting thesauri considers change in cases, abbreviations, addition of characters, typographical errors and a combination of these. Although listing out these terms is manual and tedious, it only needs to be done once and can be re-used and forms the basis for future text matching and as a training set to automate finding similar terms. This was preferred over selection based on regular expressions as when parsing these terms, there are complex patterns in the terms used and the inconsistencies in the way they are written that can be understood by a person with a geological background but not by a simple regular expression. The complexity of the regular expression required to catch all the terms of interest means an optimal expression is difficult, if not impossible, to define, and also tends to be computationally burdensome. dh2loop 1.0 provides several thesauri that can easily be updated (if needed) for the following attributes (Appendix B: Thesauri):

1. Drill hole collar elevation (Appendix B1): 360 synonyms such as "elevation" and "relative level"

2. Drill hole maximum depth (Appendix B2):160 synonyms such as "end of hole", "final depth" and "total depth"

3. Drill hole survey azimuth (Appendix B3): 142 synonyms

4. Drill hole survey dip (Appendix B4): 8 synonyms such as "inclination"

5. Drill hole lithology (Appendix B5): 688 synonyms such as "geology", "Lithology_A", "Major_Geology_Unit" and "Major_Rock_Type"

6. Drill hole comments (Appendix B6): 434 synonyms such as "description"

The thesauri created specifically for further processing lithology and comments information are:

7. Drill hole lithology codes thesaurus (Appendix B7, discussed further in Sect. 2.5.1)

8. Clean up dictionary (Appendix B8, discussed further in Sect. 2.5.2)

9. Lithology hierarchical thesaurus (Appendix B9, discussed further in Sect. 2.5.3)

In order to extract the other attributes we envisage developing other thesauri, following the same workflow.

\subsubsection{Drill hole lithology codes}

This is a thesaurus compiling the equivalent lithology for a given lithological code based on the reports submitted to GSWA. This thesaurus is identified by a company id and report number. The current thesaurus covers 41 out of the 168 companies in the study area with a total of 352 entries (Appendix B7). It is important to note that the Company_Lithocode varies depending on the CompanyID. For example, "Company 551" refers to "Saprolite" as "CS" while Company "2551" uses CS to refer to "Cambrian Sediment". The opposite is true as well, a company may use "AMPH" to refer to "Amphibolite" while another company may use "MAA".

\subsubsection{Clean-up Dictionary}

The clean-up dictionary is a list of words and non-alphabetic characters that are used as descriptions in the geological logging syntax. This dictionary is used to remove these terms from the lithology and/or comment free text descriptions prior to the fuzzy string matching. The dictionary is composed of 1662 records, most of which were compiled from abbreviations in field and mine geological mapping (Chace, 1956) and the CGI vocabularies: GeoSciML and EarthResourcesML (Simons et al., 2006; Richard et al., 2007; Raymond et al., 2012). 353 of these records are original to dh2loop and were added to accommodate the geological logging syntax in Western Australia. Added records include the following:

1. Chronostratigraphic ages (Cambrian, Proterozoic) 
2. Location descriptors (above, below, between), relative time (ancient, older, youngest)

3. Structural descriptors (anticlinal)

4. Textures (rounded, angular, block)

5. Mineralisation-related terminologies (absent, massive, disseminated)

6. Minerals (bornite, cassiterite),

7. Colors (brownish, cream)

8. Adjectives and their root form (good, better, best, extremely, extreme, fragmental, fragments, fragment)

9. Symbols (>, ?,\,@); and

10. Common phrases (same as above, as per usual).

\subsubsection{Lithology Hierarchical Thesaurus}

The lithology hierarchical thesaurus is a list of 757 rock names (Detai 1ed_Li thology), their synonyms and a two-level upscale grouping (Lithology_Subgroup and Lithology_Group). Each row in Detai 1ed_Lithology refers to a rock name. Each rock name row lists the standardized terminology first, followed by its synonyms. The two corresponding columns for this row indicated the two-level upscale grouping. 169 of these rock names were compiled from GeoSciML (Simons et al., 2006;Richard et al., 2007;Raymond et al., 2012). The synonyms were obtained from mindat.org (Ralph and Chau, 2014;Ralph, 2004). The hierarchical classification was inherited from both mindat.org (Ralph and Chau, 2014;Ralph, 2004) and the British Geological Survey (BGS) Classification Scheme (Gillespie and Styles, 1999;Robertson, 1999;Hallsworth and Knox, 1999;McMillan and Powell, 1999;Rosenbaum et al., 2003). It is important to use multiple libraries to be able to build an exhaustive thesauri as some libraries are limited by the nomenclature, level of interest and presence of the lithology or rock group in a geographic area. For example, the BGS classification did not have a comprehensive regolith dictionary, but one could argue that this is because the regolith is not extensive and not known to be a host for mineralisation in the United Kingdom. Thus, regolith has been classified using the regolith glossary (Eggleton, 2001).

The hierarchical classification consists of seven major lithology groups (Li thology_Group) (Fig. 4):

1) Igneous rocks. The igneous rocks are further classified to 12 lithology subgroups, considering grain size, composition and a combination of both.

2) Sedimentary rocks. Sedimentary rocks sub-classified to 16 lithology subgroups based on genetic source and composition (carbonate, clastic, evaporate, hybrid, hydroxide, ironstone, non-clastic siliceous, organic-rich, phosphate, siliceous, siliciclastic, volcaniclastic, glacigenic).

3) Metamorphic rocks. Metamorphic rocks are subdivided into nine lithology subgroups based on the degree and type of metamorphism (metasomatic, contact, low-grade, schist, gneiss, high-grade, granofels, greenschist, metacarbonate).

4) Surficial rocks. Surficial rocks are subdivided into 13 lithology subgroups based on the depositional environment and composition. The residual deposit Li thology_Subgroup includes the regolith detailed lithologies.

5) Mineralisation. Mineralisation is considered as a separate classification to be able to classify ore zones.

6) Structure and texture. Since structures and textures can sometimes be logged as lithologies in geological logging, they are classified separately. Structure and Texture is divided into five lithology subgroups: fault rock, breaks, contact, fillings and sedimentary structures. And

7) Unclassified. The final classification is a catch-all for unclassified rocks. 
https://doi.org/10.5194/gmd-2020-391

Preprint. Discussion started: 4 February 2021

(c) Author(s) 2021. CC BY 4.0 License.

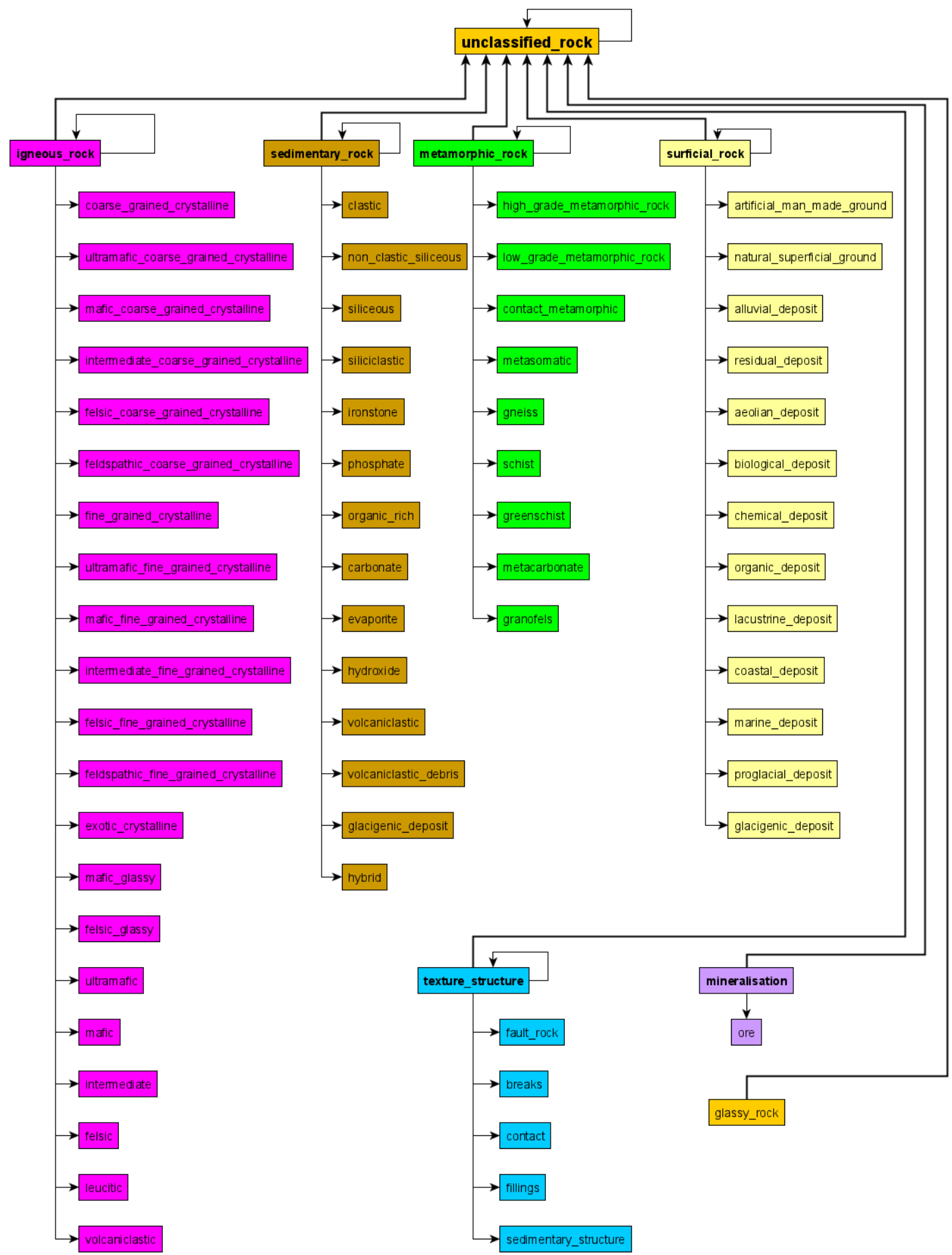

Figure 4. Lithology hierarchical thesauri showing the 7 major Lithology_Groups and their corresponding 300 Lithology_Subgroups: Igneous rocks (pink), Sedimentary rocks (light brown), Metamorphic rocks (green), Surficial Rocks (light yellow), Texture and Structure (blue), Mineralisation (purple) and Unclassified Rocks (dark yellow). Igneous rocks Li thology_Subgroups considers grain size, composition and a combination of both. Sedimentary rocks are sub-classified based on genetic source and composition. Metamorphic rocks are subdivided based on the degree and type of metamorphism. Surficial rocks are subdivided based on the depositional environment and composition. Mineralisation is considered as a separate 
https://doi.org/10.5194/gmd-2020-391

Preprint. Discussion started: 4 February 2021

(C) Author(s) 2021. CC BY 4.0 License.

305 classification to be able to classify ore zones. Structure and texture addresses situations that structures are logged as lithologies in geological logging. The final classification is a catch-all for unclassified rocks. 


\subsection{Data Extraction}

Currently, the dh2loop library extracts collar, survey and lithology information. It uses a configuration file (Appendix C1) that allows the user to define the inputs, which are:

1. Region of interest (in WGS 1984 lat/long); and/or

2. List of drill hole ID codes codes, if known.

3. If reprojection is desired, the EPSG code of the projected coordinate system (e.g. EPSG:28350 for MGA Zone 50; http://epsg.io)

4. The connection credentials to the local copy of the WAMEX database

5. Input and output file directories/locations

\subsubsection{Collar Extraction}

With the minimum input of a region of interest, the dh2loop library exports a Comma-Separated Values file (CSV) listing the drill holes in the area with the following information (Fig. 5):

1. Co11 arID: This is the primary key from the collar table. It is used to associate data in different tables with a single drill hole. The Co1 1arID for a drill hole is identical in all tables in order for data to be associated with that drill hole.

2. HoleID: This is the drill hole name, as the company would internally identify the drill hole.

3. Longitude and Latitude: The geographical coordinates locating the collar of the drill hole. Both values are expressed in WGS 1984 lat/long (EPSG:2436).

4. Relative level (RL): This refers to the $\mathrm{Z}$ coordinate of the collar location. This value is extracted by using the drill hole collar elevation thesaurus to filter the values referring to relative level (Fig. 5b). More than one value can be fetched due to duplicate company submissions or multiple elevation measurements, in which case the code retains the value with most decimal places assuming higher precision corresponds to better accuracy. If no elevation values are fetched from the database the entire record is skipped. Non-numeric values are also ignored.

5. Maximum depth (MaxDepth): This refers to the maximum downhole length drilled for a drill hole, commonly referred as the end-of-hole. This value is extracted by using the drill hole collar maximum depth thesaurus (Fig. 5c). Due to duplicate company submissions, there can be more than one value fetched. Since there is no submission date information, the code takes the value with largest value assuming it is the latest submission.

6. Calculated $X, Y$ values of projected coordinates: These values are commonly calculated and used to be able to plot the drill hole in a metric system to be able to accurate display and measure distance within and between drill holes. The projection system used in the calculation is based on the input specified in the configuration file (Sect. 2.4, Appendix C1) 


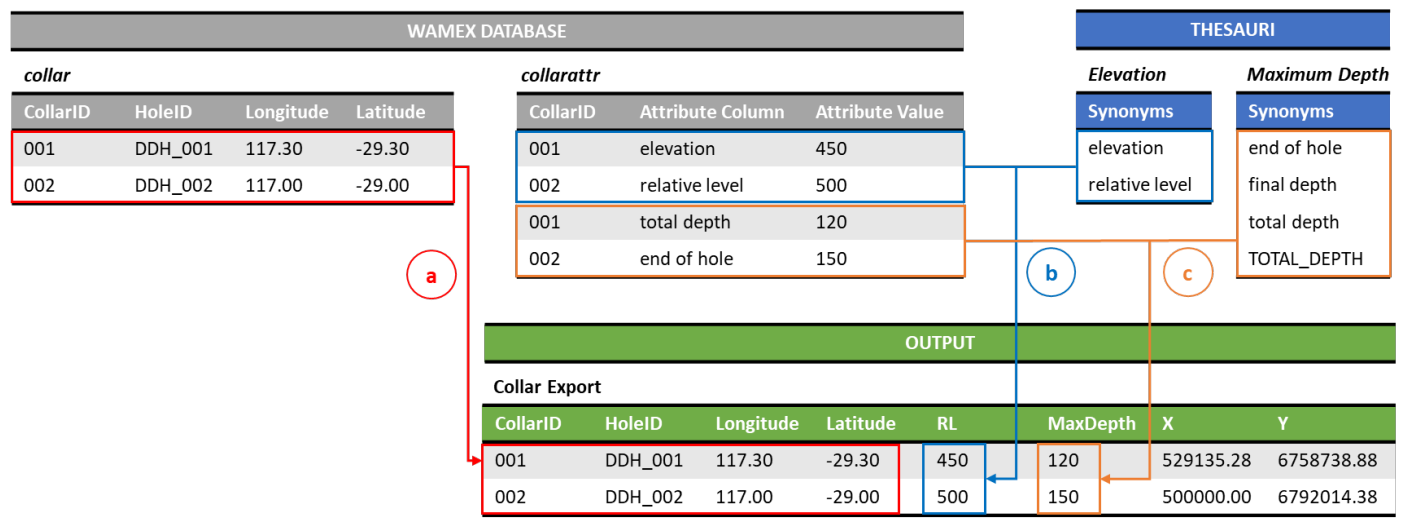

340 Figure 5. Collar extraction workflow showing the Col1 arID, HoleID, Longi tude and Latitude information is fetched from the co7 7ar table (a, red), the corresponding RL and MaxDepth values are fetched from the col 7arattr table using the Elevation (b, blue) and Maximum Depth thesauri (c, orange).

\subsubsection{Survey Extraction}

With the same inputs defined in the configuration file, the dh2loop library outputs a survey CSV file containing the following

information (Fig. 6):

1. Col 1arID: The primary key to link the survey information to the collar file.

2. Depth: This is from the survey table and refers to the downhole depth where the survey measurement was taken. All non-numeric values were ignored. If the depth value fetched is negative, the absolute value is taken as it may have been used to denote direction of drilling. This assumption was made as some drill holes have negative depth information that is technically not possible to have a negative length. This was done by some companies to denote that the depth measure was going upwards (usually for underground probing drill holes) rather than downhole. To put all the drill holes in the same cartesian plane, this correction was done.

3. Azimuth: It is the trend direction indicated by an angle between 0-360 degrees from the north going clockwise. This is extracted using the drill hole azimuth thesaurus (Fig. 6b). The code fetches values between 0-360 degrees, thus ignoring non-numeric value and values greater than 360 . Values between -360 to 0 are assumed to be counterclockwise from the north. If there is no survey information for a drill hole present in collar, the azimuth value is set to 0 .

4. Dip: It is the inclination angle perpendicular to the azimuth indicated by an angle between -90 to 90 . It is measured from the horizontal plane, thus a positive value would describe a drill hole deviating to the surface or points upward while a negative value would be a drill hole pointing downwards. This is extracted using the drill hole dip thesaurus (Fig. 6c).

5. Calculated $X, Y, Z$ values: These values are the project location of the survey measurement. This is calculated using the minimum curvature (also called spherical arc) algorithm. The minimum curvature algorithm (Amorin, 2009) desurveys downhole distances as distances along a circular arc. The algorithm matches the survey at two consecutive measurements exactly and the curvature is constant between these two measurements. The direction remains continuous meaning there are no sharp changes in direction. The code for the minimum curvature was based on the pyGSLIB drill hole module. 


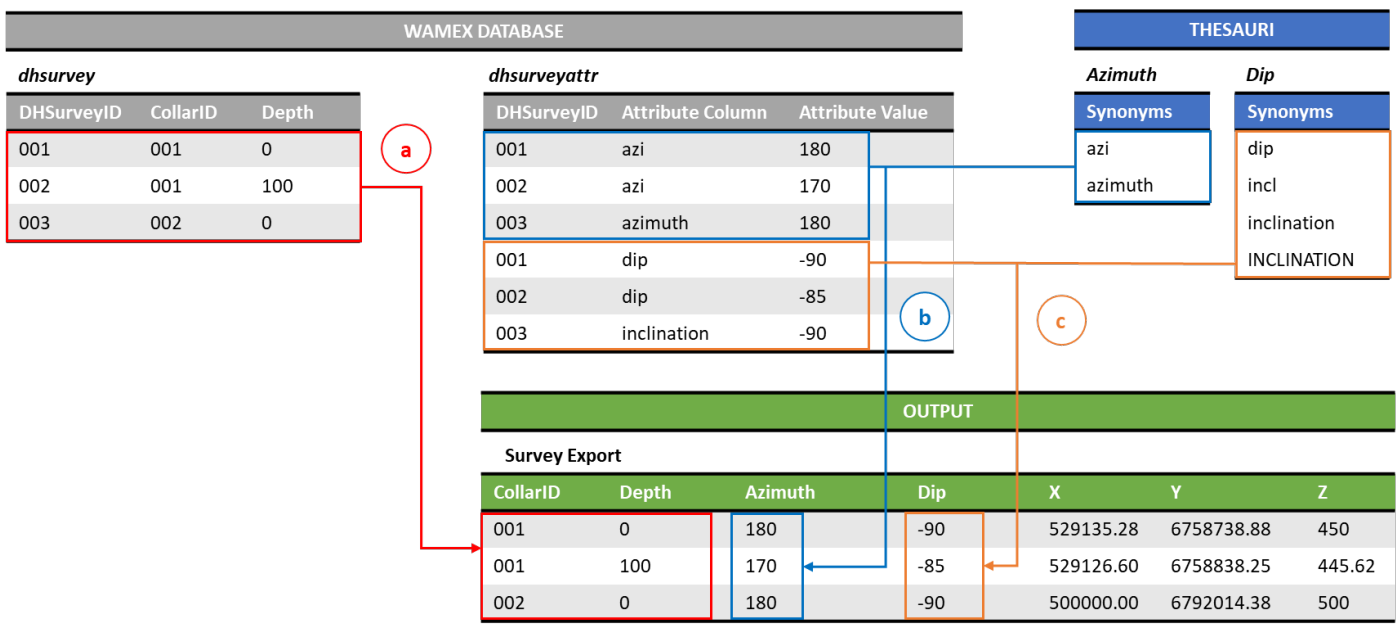

370 Figure 6. Survey extraction workflow showing the DHSurveyID, Col 1 arID and Depth information is fetched from the dhsurvey table (a, red), the corresponding Azimuth and Dip values are fetched from the dhsurveyattr table using the Azimuth (b, blue) and Dip thesauri (c, orange).

\subsubsection{Lithology Extraction}

The lithology extraction outputs a lithology CSV file containing the following information (Fig. 7):

1. CompanyID: The primary key to link the lithology code to the drill hole lithology codes thesaurus and decode the lithologies.

2. Co11 arID: The primary key to link the lithology information to the collar file.

3. FromDepth and ToDepth: The start/from and end/to downhole depth values. If the ToDepth is null, we assume ToDepth to be equal to FromDepth +0.01 . If the FromDepth is larger than ToDepth, the FromDepth and ToDepth values are switched.

4. Detai 1ed_Li thology: This value is the lithology matched through fuzzy string matching. The string that serves as input to the fuzzy string matching may either be the Company_Litho (decoded lithology from Company_LithoCode) or from the Comments (free text descriptions).

4.1. Decoding Lithological Codes

4.1.1. Company_Lithocode: This fetches the lithology codes that are typically three-letter codes using the drill hole lithology thesaurus.

4.1.2. Company_Litho: The Company_Litho is fetched by matching the CompanyID and Company_LithoCode to the drill hole lithology codes thesaurus.

4.2. Comments: This fetches the free text descriptions using the drill hole comments thesaurus.

5. Lithology_Subgroup and Lithology_Group: Upscales the lithological information to more generic rock groups. For example, Detailed_Lithology: "basalt" is upscaled to Li thology_Subgroup:"mafic_finegrained crystalline" and further upscaled to Li thology_Group:"igneous rock".

6. Calculated $\mathrm{X}, \mathrm{Y}, \mathrm{Z}$ for the start, mid and endpoint also using the minimum curvature algorithm. The desurveying code was heavily based on the pyGSLIB drill hole module. 
https://doi.org/10.5194/gmd-2020-391

Preprint. Discussion started: 4 February 2021

(c) Author(s) 2021. CC BY 4.0 License.

\begin{tabular}{|c|c|c|c|c|c|}
\hline \multicolumn{6}{|c|}{ OUTPUTS } \\
\hline \multicolumn{6}{|c|}{ dhgeology + dhgeologyattr } \\
\hline CompanylD & CollarlD & FromDepth & ToDepth & Attribute Column & Attribute Value \\
\hline CompanyA & 001 & 0 & 50 & Lithology_A & BAS \\
\hline CompanyA & 001 & 0 & 50 & Comments & dark basalt? \\
\hline \multicolumn{6}{|c|}{ THESAURI } \\
\hline Lithology & & \multicolumn{3}{|c|}{ Lithology Codes } & Comments \\
\hline Synonyms & & \multirow{2}{*}{$\begin{array}{l}\text { Company } \\
\text { LithoCode } \\
\end{array}$} & \multirow{2}{*}{\multicolumn{2}{|c|}{$\begin{array}{l}\text { Company_ } \\
\text { Litho } \\
\end{array}$}} & Synonyms \\
\hline \multicolumn{2}{|l|}{ Lithology_A } & & & & Comment \\
\hline Major_Geol & & BAS & \multicolumn{2}{|c|}{$\begin{array}{l}\text { dark Hi-Mg } \\
\text { basalt }\end{array}$} & Comments \\
\hline \multirow[t]{2}{*}{ Major_Rock } & & AND & \multicolumn{2}{|c|}{ andesite } & DESC \\
\hline & & SST & \multicolumn{2}{|c|}{ sandstone } & \\
\hline
\end{tabular}

Clean-up

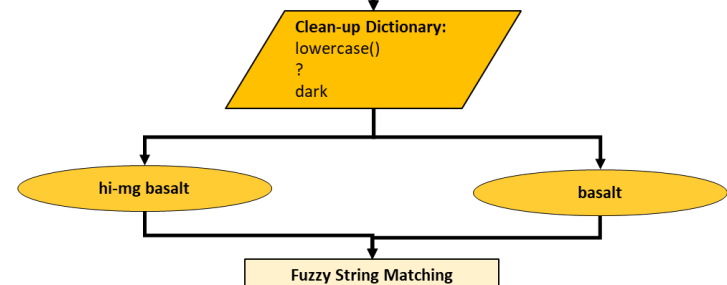

fragmenta

fragments

fragment

gray

Proterozoic

weathered
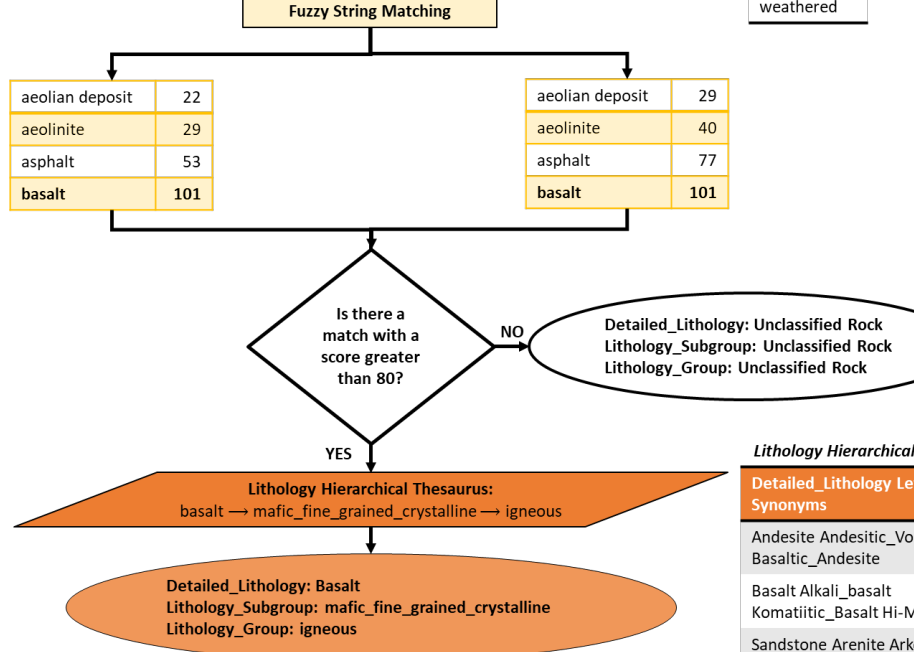

Lithology Hierarchical

\begin{tabular}{lll}
\hline $\begin{array}{l}\text { Detailed_Lithology Level } \\
\text { Synonyms }\end{array}$ & Lithology_Subgroup Level & $\begin{array}{l}\text { Lithology_Group } \\
\text { Level }\end{array}$ \\
\hline $\begin{array}{l}\text { Andesite Andesitic_Volcanics } \\
\text { Basaltic_Andesite }\end{array}$ & intermediate_fine_grained_crystalline & igneous \\
$\begin{array}{l}\text { Basalt Alkali_basalt } \\
\text { Komatiitic_Basalt Hi-Mg_Basalt }\end{array}$ & mafic_fine_grained_crystalline & igneous \\
\begin{tabular}{lll} 
Sandstone Arenite Arkose & clastic & sedimentary \\
\hline
\end{tabular}
\end{tabular}

400 Figure 7. Lithology extraction is done through the Lithology Code and Comments workflows. The values are fetched from the dhgeo logy and dhgeologyattr table (green) using either the Lithology (blue) and Lithology Code (light blue) thesauri or the Comments (blue) thesaurus. The string fetched is then cleaned prior to the fuzzy string matching using the Cleanup Dictionary (dark yellow). The result is then matched against the Detailed_Li thology level of the Lithological Hierarchical Thesaurus. If there is a match with a score greater or equal to $\mathbf{8 0}$, the match is taken and matched with the rest of the columns in the Lithology

Hierarchical thesaurus. If not, it is labelled as unclassified rock. 
Once the Company_Litho (decoded lithology from Company_Lithocode) or from the Comments (free text descriptions) have been extracted from the database, the lithology strings were pre-processed such that:

a) The strings were converted to lowercase form.

b) The string inside parenthesis, brackets and braces were removed, as these were found to reduce the accuracy of the matching.

c) The string followed by key phrases such as "with", "possibly", "similar to" were removed.

d) If any of the words listed in the clean-up dictionary were present in the string, these words were removed.

e) Lemmatization, the removal of the inflections at the end of the words in order the "lemma" or root of the words, was applied to all nouns (Müller et al., 2015).

f) All words with non-alphabetic characters and tokens with less than three characters were removed.

g) Stopwords, a set of words frequently used in language which are irrelevant for text mining purposes (Wilbur and Sirotkin, 1992), were removed. Examples on stopwords are: as the, is, at, which, and on.

This is followed by fuzzy string matching, an algorithm which finds the string that matches a pattern approximately. Fuzzy string matching is typically divided into two sub-problems: 1) finding approximate substring matches inside a given string, and 2) finding dictionary strings that match the pattern approximately. Fuzzy string matching uses the Levenshtein Distance to calculate the differences between sequences and patterns (Okuda et al., 1976; Cohen, 2011). The Levenshtein distance measures the minimum number of single-character edits (insertion, deletion, substitution) necessary to convert a given string into an exact match with the dictionary string (Levenshtein, 1965).

We utilized fuzzywuzzy (https://github.com/seatgeek/fuzzywuzzy) for this. fuzzywuzzy provides two methods to calculate a similarity score between two strings: ratio() or partial_ratio(). It also provides two functions to pre-process the strings: token_sort() and token_set(). In this work, we used the token_set_ratio() scorer to do fuzzy string matching to classify the database lithology description into one of the lithology thesaurus entries (Table 1). token_set() pre-processes the strings by: 1) splitting the string on white-spaces (tokenization), 2) turning to lowercase and 3) removing punctuations, non-alpha nonnumeric characters and unicode symbols. It tokenizes both strings (given string and dictionary string), splits the tokens into: intersection and remainder, then sort and compare the strings. Since the sorted intersection component of token_set(), will result in an exact match, the score will tend to increase when: 1) the sorted intersection makes up a larger percentage of the full string, and 2) the remainder component are more similar. The ratio() then computes the standard Levenshtein distance between two strings. token_set_ratio() was found to be effective in addressing harmless misspelling and duplicated words but sensitive enough to calculate lower scores for longer strings (3-10 word labels), inconsistent word order and missing or extra words. partial_ratio() which takes the "best partial" of two strings or the best matching on the shorter substring was not preferred as it does not address the difference and order in substring construction. token_sort() was not preferred as it alphabetically sorts the tokens that ignores word order and does not weight intersection tokens which does not address the behavior of the strings in the logs. 
Table 1. Examples of fuzzy string matching output using different combinations of the fuzzywuzy functions. The table demonstrates the corresponding effect of these functions to the given string. Token_set_ratio () works best on geological free text descriptions as it 445 weights the intersection tokens, honors substring construction and word order and ignores misspelling, extra and duplicated words. Partial_ratio () ignores substring construction and order and is more sensitive to misspellings. Token_sort_ratio $O$ also ignores substring order and does not recognize duplicate and extra words.

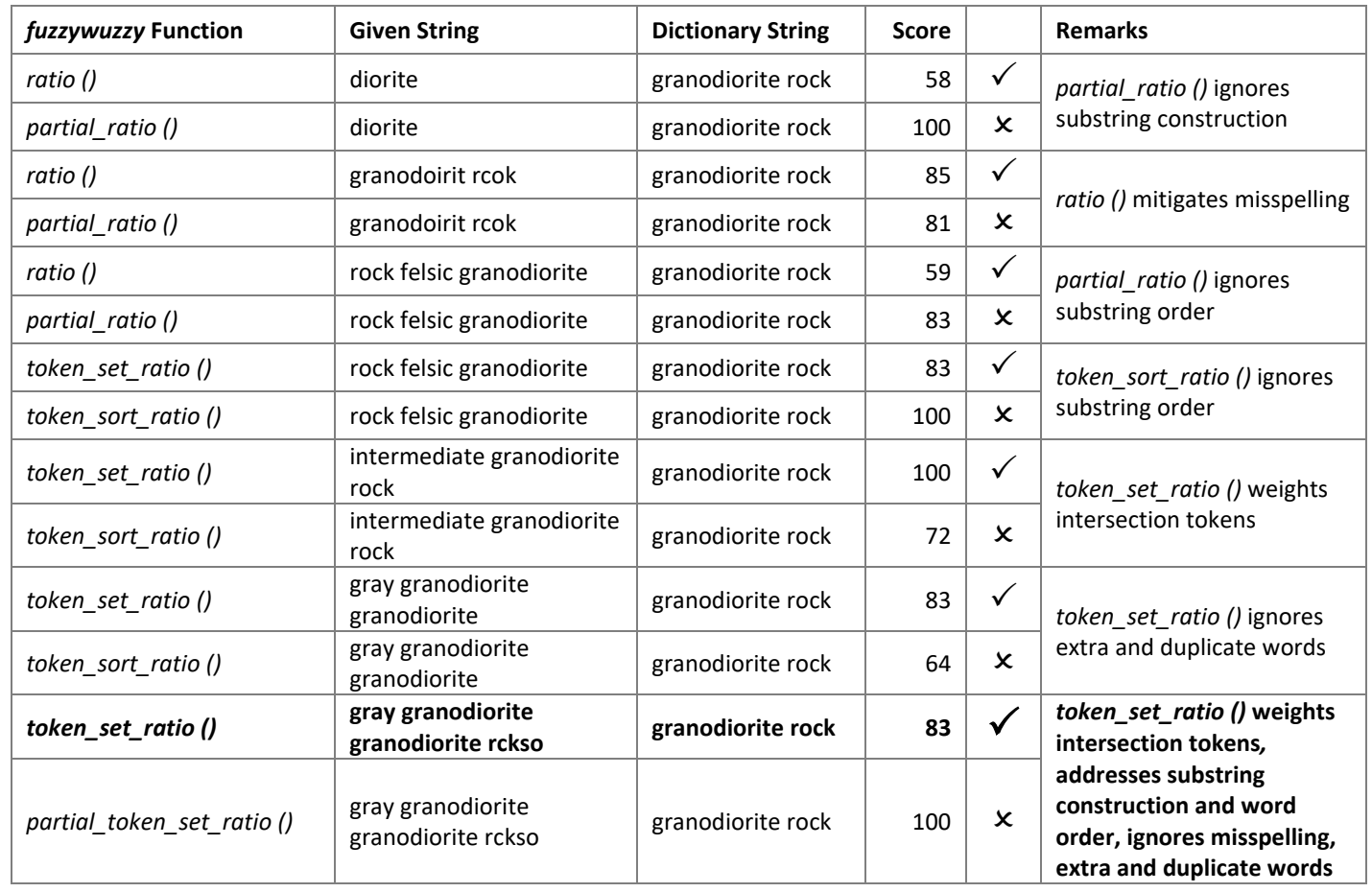

450 The code calculates the token_set_ratio() between the Company_Li tho or Comments (given string) and the entries in the lithology hierarchical thesaurus (dictionary string). The tendency of geologists when describing rocks is to enumerate the descriptors before the rock name. For example, if the lithology in the logged interval is "basalt", the free text description could be something like "Dark gray to dark reddish brown, with olivine phenocrysts, largely altered andesitic basalt". After processing the string, it will be left with "andesitic basalt". To avoid, misclassifying the rock to "andesite", a bonus score is

455 also added to add weight to the last word (in this case, "basalt") (Appendix C2 Pseudocode). For the pair between Company_Litho or Comments and the entries in the lithology hierarchical thesaurus with the highest score, the first synonym is stored as Detailed_Lithology. If the score is less than 80 , it is classified as "unclassified rock". The cut-off value of 80 is user-defined, and in this case chosen based on the performance of the matching on a subset of 1,548 unique lithology codes (Fig. 8) from a subset of the YSGB dataset in the Golden Grove area. The matching performance may vary depending on the dataset being extracted. It is advised to test in a subset and adjust these cut-off score depending on these results. If the performance is significantly lower, this indicates that the thesauri used in dh2loop may not be suitable to your area. The user may opt to update these thesauri to suit their needs. Once matched on Detailed_Lithology, the corresponding Li thology_Subgroup and Li thology_Group classifications are also fetched. 


\section{Cut-off Score Determination}

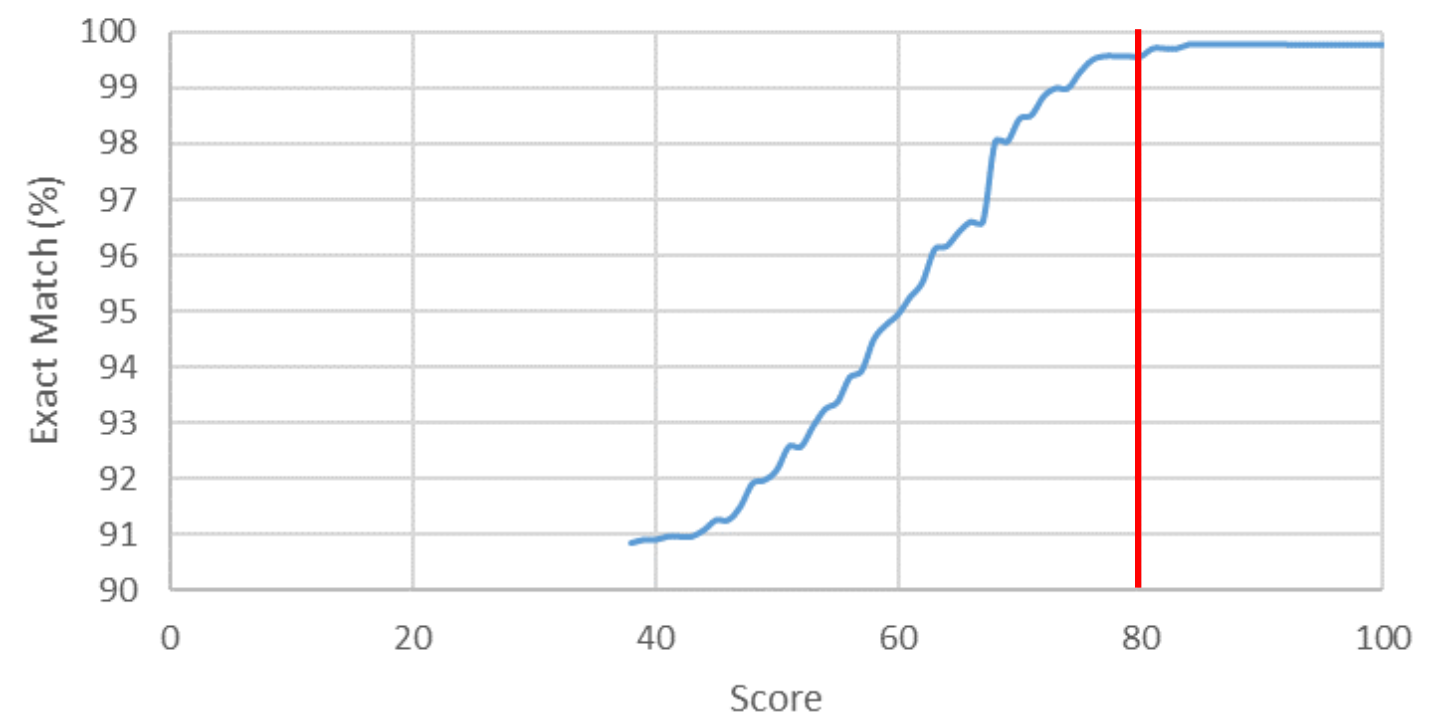

Figure 8. The user-defined cut-off score of 80 was chosen based on the results of the testing different cut-offs on a smaller dataset within the YSGB area. As seen in this figure, the number of exact matches plateau at a score of 80 . This relationship may vary depending on the datasets available in the area. Thus, this cut-off value is user-defined and is best to test the matching performance on a subset in the user's area.

\section{Data Extraction Results}

\subsection{Collar}

Extraction of the collar data for YSGB resulted in a collar file with 68,729 drill holes (Table 2). This information was extracted from the co 7 7ar table with 73,881 drill holes with 769,981 rows of information from co 7 7arattr. It includes the location of the collar both in geographic and projected coordinated systems, relative level (RL) and maximum depth (MaxDepth). A total of 136,100 records for RL were retrieved from the database, 1,526 of which were disregarded: 846 records for having an $\mathrm{RL}$ value greater than 10,000 meters and 680 non-numeric records. These discarded values were retrieved from the attribute column "RL_Local". In spite of it being an isolated issue for "RL_Local", the attribute column was retained as it is retrieved sensible values for other companies. The discarded values were limited to data from two companies $(4085,4670)$ for RL attribute columns "TD" and "DEPTH". A total of 58,706 records for MaxDepth were retrieved from the database: 58,642 of which were extracted as is, while 64 entries were disregarded for having a value of -999 . The discarded values come from 8 companies. Null values are assigned to disregarded and absent RL or MaxDepth values. The "clean" collar export file contains at least either a value for RL or MaxDepth. The reasoning behind keeping records with at least one of the two field is there are other ways to extract for RL or MaxDepth from the database. RL values can be extracted from digital terrain models and MaxDepth values can be taken for the largest ToDepth values from the other tables.

\subsection{Survey}

For the survey extraction, the dhsurvey table contained 146,713 survey depth intervals (from 45,708 drill holes) with corresponding 850,507 entries of supplementary survey information in dhsurveyattr (Table 3). Survey extraction in YSGB resulted in 126,669 survey depth information across 45,708 drill holes with azimuth (-52.5 to 359) and dip measurements (0-90) for each depth interval. A total of 517,592 records for Azimuth were retrieved from the database. 77 
Azimuth values greater than 360 were retrieved and thus disregarded. 152 values were non-numeric values and were also disregarded. These discarded values involved 228 holes across 10 companies. A value of 0 was assigned to missing Azi muth values. A total of 118,223 records for Dip were fetched from the database, 118,138 of which were extracted as is, while 95 entries were disregarded for having a value greater than 90 . A values of -90 was assigned as the default for Dip. The discarded values correspond to 94 drill holes across 5 companies.

\subsection{Lithology: Lithology Code and Comments workflow}

Lithology extraction is divided into two workflows. For the Lithology Code workflow, the extraction starts with filtering the dhgeology and dhgeologyattr table by the location extents and the Lithology thesaurus. The dhgeology table contained 47,062 drill holes across 115 companies with 797,975 lithology depth intervals with corresponding 820,612 entries of lithology information in dhgeologyattr. These records were matched with the entries from the Lithology Code 500 thesaurus resulting to 273,684 matched records. The FromDepth and ToDepth for these records were then validated. 74 records had equal FromDepth and ToDepth values. 654 had values for FromDepth but null values for ToDepth. For both cases, ToDepth was calculated as FromDepth+0.01. The Lithology Code workflow resulted to 273,684 intervals across 12,793 drill holes wherein 235,606 records were successfully matched in the fuzzy string matching.

505 The Comments workflow extracts the records from the dhgeology and dhgeologyattr table as well, but this time using the Comments Thesaurus. For YSGB, the database has 262,567 records across 22,766 drill holes with comments. Since the comments are extracted here to compare their results from fuzzy string matching, only those records that matched in the Lithology Code workflow were retained. This resulted to 47,823 records, however, only 7,870 records were successfully matched on Comments. The dataset for the fuzzy string matching assessment (Sect. 5) consists only of the unique records

510 matched on both workflows (3,074 records). It was visually checked from the records that the Lithology Code Detai 1ed_Li thology results were sound classifications of the Company_Li thology. This was done to make sure that these results could be considered as the "true value" in the fuzzy string matching assessment (Sect. 5). 

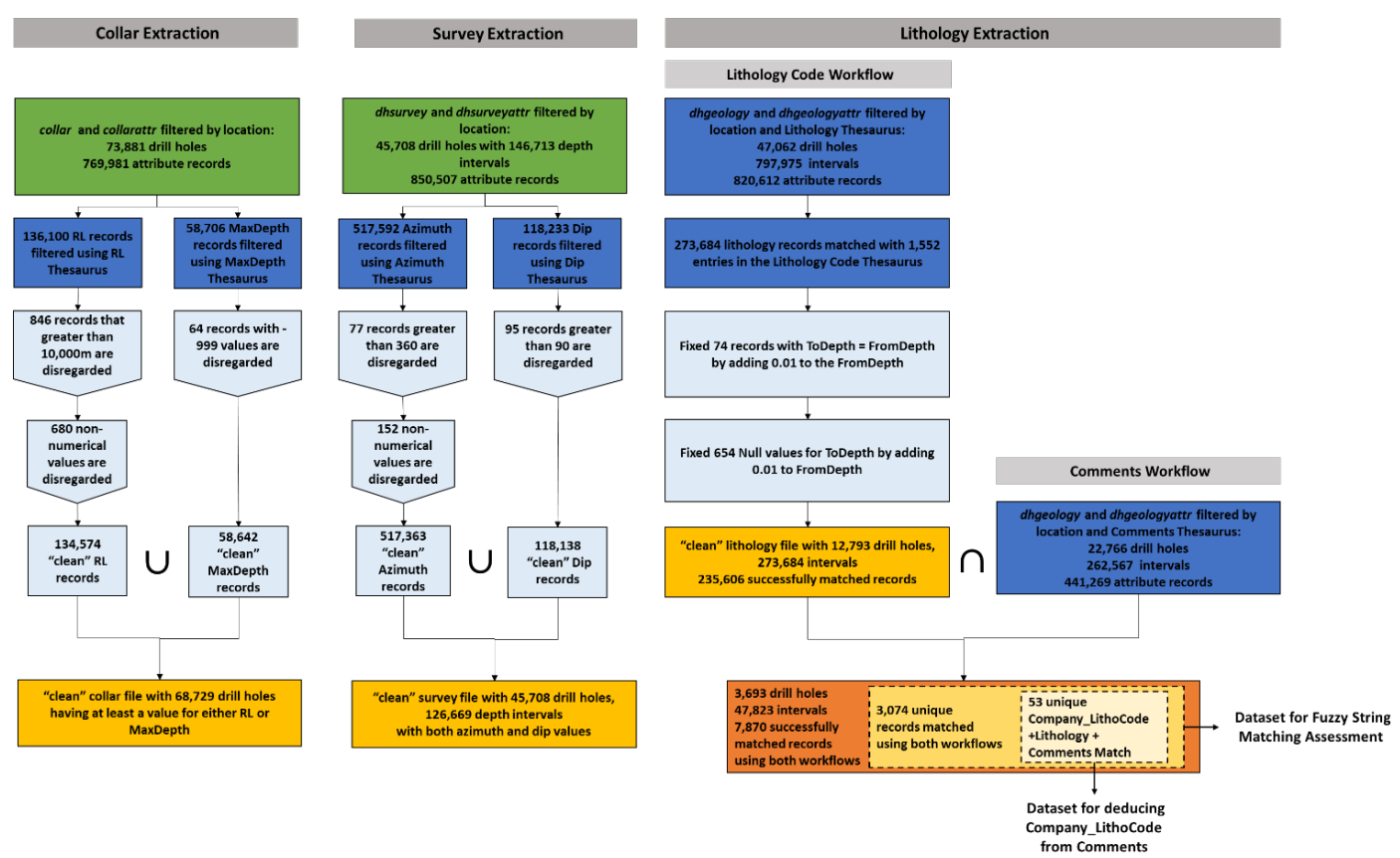

515 Figure 9. Extraction of the collar, survey and lithology data for the YSGB. The collar extraction resulted in a collar file with 68,729 drill holes from the co77ar table with $\mathbf{7 3 , 8 8 1}$ drill holes with 769,981 rows of information from co 7 7arattr. A total of 136,100 records for RL were retrieved from the database, 1,526 of which were disregarded: 846 records for having an RL value greater than 10,000 meters and 680 non-numeric records. A total of 58,706 records for MaxDepth were retrieved from the database: $\mathbf{5 8 , 6 4 2}$ of which were extracted as is, while 64 entries were disregarded for having a value of -999 . The "clean" collar export file contains at

520 least either a value for RL or MaxDepth. Survey extraction in YSGB resulted in 126,669 survey depth information across 45,708 drill holes. The dhsurvey table contained 146,713 survey depth intervals (from 45,708 drill holes) with corresponding 850,507 entries of supplementary survey information in dhsurveyattr. 77 Azimuth values greater than 360 and 152 values were nonnumeric values. Lithology extraction is divided into two workflows. For the Lithology Code workflow, the extraction starts with filtering the dhgeology and dhgeologyattr table by the location extents and the Lithology thesaurus. The dhgeology table

525 contained 47,062 drill holes across 115 companies with 797,975 lithology depth intervals with corresponding 820,612 entries of lithology information in dhgeologyattr. These records were matched with the entries from the Lithology Code thesaurus resulting to 273,684 matched records. The FromDepth and ToDepth for these records were then validated. 74 records had equal FromDepth and ToDepth values. 654 had values for FromDepth but null values for ToDepth. For both cases, ToDepth was calculated as FromDepth+0.01. The Lithology Code workflow resulted to 273,684 intervals across 12,793 drill holes wherein 235,606 records

530 were successfully matched in the fuzzy string matching. The Comments workflow extracts the records from the dhgeology and dhgeologyattr table as well, but this time using the Comments Thesaurus $(262,567$ records across 22,766 drill holes with comments). 47,823 records were present in both workflows, 7,870 records of which were successfully matched. The 3,074 unique entries from this was used as the dataset for the fuzzy string matching assessment (Sect. 5). 
Using the Company_Lithocode, Lithology_Code Detailed_Lithology and Comments Detailed_Lithology from the dataset for the fuzzy string matching assessment, we can assess if matches using the Comments workflow alone can sufficiently decode lithology. Excluding the unmatched entries and taking only the unique combinations of Company_LithoCode, Lithology_Code Detailed_Lithology and Comments Detai 1ed_Li thology, the dataset results into 53 unique records.

To be able to assess the matching we take a look at the type of matches between Lithology_Code Detailed Lithology and Comments Detailed_Lithology. First, we define a match as retrieving an answer from the fuzzy string matching with a score greater than 80. It is important to note here that it only suggests that it succeeded to find an answer above the score threshold but not necessarily mean that it is the correct answer. To further describe the quality of a match, we modified for this purpose the following terminologies from the Simple Knowledge Organization System (Miles and Bechhofer, 2009):

a) Exact Match suggests that both workflows resulted in the same classification at all 3 levels. The match at the Detailed_Lithology level has an exact match, thus resulting to an exact match on the other two levels.

b) Close Match suggests that the results at the Detailed_Li thology level are related rocks and belong to the same Li thology_Subgroup. This is usually caused by differing use of lithological nomenclature.

c) Related Match suggests that the results at the Detai 1ed_Li thology level are related rocks and belong to the same Lithology_Group.

d) Broad Match refers to the Detailed_Lithology from Lithology Code workflow matches to a Lithology_Subgroup in the Comments workflow.

e) Narrow Match is the logical equivalent of a Broad Match. In this case, the Comments workflow resulted in a Detai 1ed_Li thology level while the Lithology Code workflow resulted in a Li thology_Subgroup level.

f) Broader Match is similar to a broad match except that the Detailed_Lithology from Lithology Code workflow matches to a Li thology_Group instead of a Lithology_Subgroup in the Comments workflow.

g) Narrower Match is the logical equivalent of Broader Match. The Comments workflow results to a Detailed_Li thology while the Li thology_Code workflow results to a Li thology_Group level.

h) Failed Match suggests all levels of both workflows do not match. This is usually attributed to contrasting information from both fields or the algorithm fails. This category is an addition to the SKOS reference. 
Table 2. Fuzzy string matching terminology used to describe the quality of matches based on the Simple Knowledge Organization System (SKOS) (Miles and Bechhofer, 2009). The values being compared are the Detai 1 ed_L $i$ thology level for both Lithology 570 Code and Comments workflow (brown text). The level at which the records are considered to match are in bold. A Match retrieves an answer from the fuzzy string matching with a score greater than 80. An Exact Match suggests that both workflows resulted in the same classification at all 3 levels. A Close Match suggests that the results at the Detai led_Li thology level are related rocks and belong to the same Lithology_Subgroup. A Related Match suggests that the results at the Detailed_Lithology level are related rocks and belong to the same Lithology_Group. A Broad Match refers to the Detailed_Lithology from 575 Lithology Code workflow matches to a Li thology_subgroup in the Comments workflow. Narrow Match is the logical equivalent of a Broad Match. Broader Match is similar to a broad match except that the Detailed_Lithology from Lithology Code workflow matches to a Li thology_Group instead of a Li thology_Subgroup in the Comments workflow. Narrower Match is the logical equivalent of Broader Match. A Failed Match suggests all levels of both workflows do not match.

\begin{tabular}{|c|c|c|c|c|c|c|}
\hline $\begin{array}{l}\text { Lithology } \\
\text { Code } \\
\text { Detailed } \\
\text { Lithology } \\
\text { Level }\end{array}$ & $\begin{array}{l}\text { Comments } \\
\text { Detailed } \\
\text { Lithology } \\
\text { Level }\end{array}$ & $\begin{array}{l}\text { Lithology } \\
\text { Code } \\
\text { Lithology } \\
\text { Subgroup } \\
\text { Level }\end{array}$ & $\begin{array}{l}\text { Comments } \\
\text { Lithology } \\
\text { Subgroup } \\
\text { Level }\end{array}$ & $\begin{array}{l}\text { Lithology } \\
\text { Code } \\
\text { Group } \\
\text { Level }\end{array}$ & $\begin{array}{l}\text { Comments } \\
\text { Group Level }\end{array}$ & $\begin{array}{l}\text { Type of } \\
\text { Match }\end{array}$ \\
\hline basalt & basalt & & & & & Exact Match \\
\hline basalt & $\begin{array}{l}\text { basic } \\
\text { volcanic } \\
\text { rock }\end{array}$ & $\begin{array}{l}\text { mafic fine } \\
\text { grained } \\
\text { crystalline }\end{array}$ & $\begin{array}{l}\text { mafic fine } \\
\text { grained } \\
\text { crystalline }\end{array}$ & & & $\begin{array}{l}\text { Close } \\
\text { Match }\end{array}$ \\
\hline basalt & gabbro & $\begin{array}{l}\text { mafic fine } \\
\text { grained } \\
\text { crystalline }\end{array}$ & $\begin{array}{l}\text { mafic coarse } \\
\text { grained } \\
\text { crystalline }\end{array}$ & igneous & igneous & $\begin{array}{l}\text { Related } \\
\text { Match }\end{array}$ \\
\hline basalt & $\begin{array}{l}\text { mafic fine } \\
\text { grained } \\
\text { crystalline }\end{array}$ & $\begin{array}{l}\text { mafic fine } \\
\text { grained } \\
\text { crystalline }\end{array}$ & $\begin{array}{l}\text { mafic fine } \\
\text { grained } \\
\text { crystalline }\end{array}$ & & & $\begin{array}{l}\text { Broad } \\
\text { Match }\end{array}$ \\
\hline $\begin{array}{l}\text { mafic fine } \\
\text { grained } \\
\text { crystalline }\end{array}$ & basalt & $\begin{array}{l}\text { mafic fine } \\
\text { grained } \\
\text { crystalline }\end{array}$ & $\begin{array}{l}\text { mafic fine } \\
\text { grained } \\
\text { crystalline }\end{array}$ & & & $\begin{array}{l}\text { Narrow } \\
\text { Match }\end{array}$ \\
\hline basalt & mafic & $\begin{array}{l}\text { mafic fine } \\
\text { grained } \\
\text { crystalline }\end{array}$ & mafic & igneous & igneous & $\begin{array}{l}\text { Broader } \\
\text { Match }\end{array}$ \\
\hline mafic & basalt & mafic & $\begin{array}{l}\text { mafic fine } \\
\text { grained } \\
\text { crystalline }\end{array}$ & igneous & igneous & $\begin{array}{l}\text { Narrower } \\
\text { Match }\end{array}$ \\
\hline basalt & sandstone & $\begin{array}{l}\text { mafic fine } \\
\text { grained } \\
\text { crystalline }\end{array}$ & clastic & igneous & sedimentary & $\begin{array}{l}\text { Failed } \\
\text { Match }\end{array}$ \\
\hline
\end{tabular}




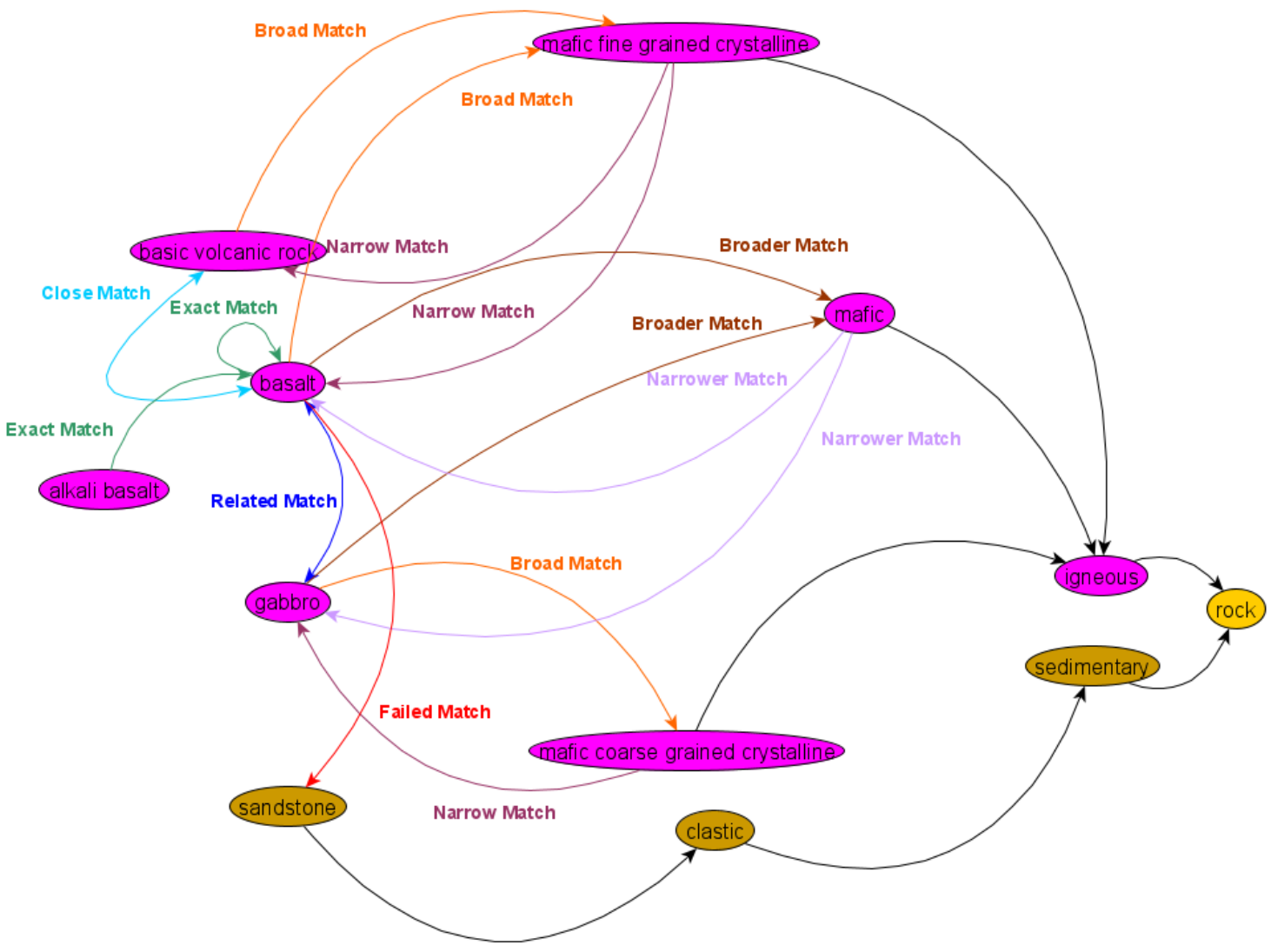

Figure 10. SKOS graph showing the semantic, associative and hierarchical relationship in the Lithology Hierarchical Thesaurus. In this example, terms "basalt" and "alkali basalt" are judged to be sufficiently the same to assert an Exact Match relationship (in green). "basic volcanic rock" however is considered a Close Match (in cyan) and "gabbro" a Related Match (in blue). "mafic fine grained crystalline" and "mafic coarse grained crystalline" are broader concepts, thus considered a Broad Match (in orange) to "basalt" and "gabbro" respectively. Broader Match (in brown) are similar to Broad Matches but are used to refer a wider semantic difference between the two concepts. Narrow Matches (in light purple) and Narrower Matches (in dark purple) are the logical equivalent of Broad Match and Broader Match. Failed Matches is used to describe unrelated matches.

34 out of the 53 unique entries (64\%) result to matches between the Detailed Lithology and Comments Detailed_Lithology. 26 of which are Exact Matches, 19 unique entries are Close Matches and 26\% percent are Failed Matches. The Failed Matches are due to unrelated descriptions in the Comments field which was used to obtain the results in Comments Detailed_Lithology. An example of this is the interval is logged as "ironstone" but the comments contain "mafic schist". Another less common reason is the Company_LithoCode is repeated in the Comments. An example of this is would be an interval logged as "colluvium" and the Comments as "COL". The Comments workflow will result to "coal" instead.

\section{$5 \quad$ Fuzzy String Matching Results}

We present results from the data extraction using both workflows: Lithology Code and Comments. The overlaps between these two workflows suggest that the user may need to make choices to identify which is better suited for matching in their area of interest. To better understand the difference between these results, we take a looks at the matching overlaps between the two workflows (3,074 entries). These matching overlaps are used to compare and describe the fuzzy string matching using the decoding the lithology codes and using the comments free text descriptions. 
Exact Matches: Of the total matched entries, 944 were Exact Matches (31\%) (Table ). The Exact Matches are ideal outcomes as both workflows resulted in exactly the same answers.

Close Matches: The Close Matches are common for coarse-grained igneous rocks, clastic sedimentary rocks, surficial residual rocks and filling structures. The coarse-grained igneous rocks such as gabbro, gabbroid and dolerites are used interchangeably in both fields. Comments can contain terminologies such as "gabbroic", "granophyric gabbro to dolerite", "intrusive granitoid to gabbro" resulting to close matches. Similar cases are observed between granodiorite and granite and between peridotite and coarse-grained ultramafic rocks. For clastic sedimentary rocks, the Close Matches are a result of gradation of grain size in the comments field. For example, an interval logged as mudstone is then described in the comments as "mudstone to sandstone" or "intercalated with siltstone". These comments will result in "sandstone" and "siltstone", respectively. Both clastic sedimentary rocks but not an Exact Match to mudstone. Metasediments and quartz veins occur together and what is described last dictates the Detai 1ed_Li thology classification. Surficial rocks such as soil, duricrust, colluvium, laterite, calcrete, ferricrete and cover are used loosely or occur together resulting to multiple combination of these Close Matches.

Related Matches: 60 entries (3\%) resulted in related matches. For igneous rocks, this result is observed when the comments field use rock type descriptors such as "komatitic", "basaltic" and "doleritic". An example would be an interval logged as dolerite and is then described in the comments as "dolertic basalt". This would result in dolerite in the Lithology Code workflow and "basalt" in the Comments workflow. Both lithologies are igneous, however have different composition and textural implications. For sedimentary rocks, Lithology Code workflow results to sedimentary rocks classified based on grain size as they have been logged ("gravel", "mud"). The comments field contains compositional descriptions such as "with silcrete" or "minor chert". In this case, the comments workflow will result in "silcrete" and "chert". Both workflows will result in sedimentary rocks, but the Lithology Code workflow will result in "clastic" rocks while the comments workflow will classify these to "siliceous" at the Lithology_Subgroup level. The related matches for structures occur across coincident lithologies such as "mylonite", "vein", "fault" and "breccia" which could either be "fillings" or "fault_rock" at the Lithology_Sugbroup.

Broad and Narrow Matches: No broad matches were noted and only one narrow match was obtained (Table 3). The interval was logged as "ironstone" with "BIF" in the comments, "ironstone" being a more general description for "banded iron formation".

Broader and Narrower Matches: More common cases are Broader and Narrower Matches indicate that there is a bigger relationship gap between the data in the lithology and comments field. Broad matches are a result of low detail comments. For example, an interval logged as "gabbro" is described as "medium-grained mafic", "massive mafic", "rich mafic". The inverse is noted for narrower matches, the interval is logged as "sediment" but in the comments the interval is described as "siliceous sediments".

Failed Matches: 1,694 entries resulted in Failed Matches (55\%). Failed Matches occur when the lithology and comments field contain different information. This could be because of the lithology contains the main lithology while the comments

640 contains all other lithologies intercalated in the interval. Another reason is the lithology field is relogged based on adjacent intervals without amending the comments. "Mudstone" had failed matches with a wide range of lithologies, such as: "amphibolite", "dolerite", "saprolite", “duricrust", "laterite", "banded iron formation", "chert", "phyllite”, "schist”, "vein”. 
The same is observed for igneous rocks such as: "coarse-grained-ultramafic-rock". For "chert", the failed matches are within a range of sedimentary rocks: "alluvium” and "mud", "amphibolite” and "massive sulphide", "carbonate", "vein”, "pegmatite".

Table 3. Distribution of matches across the Fuzzy String Matching Dataset. A total of $45 \%$ of the unique records were matched reasonably, 31\% of which are Exact Matches, $6 \%$ Close Matches, 3\% Related Matches, 3\% Broader Matches and 3\% Narrower Matches.

\begin{tabular}{|l|r|r|}
\hline \multicolumn{1}{|c|}{ Type of Match } & Number of Entries & Percent \\
\hline Exact Match & 944 & $31 \%$ \\
\hline Close Match & 197 & $6 \%$ \\
\hline Related Match & 60 & $3 \%$ \\
\hline Broad Match & 0 & $0 \%$ \\
\hline Narrow Match & 1 & $0 \%$ \\
\hline Broader Match & 84 & $3 \%$ \\
\hline Narrower Match & 95 & $3 \%$ \\
\hline Failed Match & 1694 & $55 \%$ \\
\hline TOTAL & $\mathbf{3 , 0 7 4}$ & $\mathbf{1 0 0 \%}$ \\
\hline
\end{tabular}

The matching results can be visualized as confusion matrices, which are typically used in machine learning to compare the performance of an algorithm versus a known result. In this case, we are comparing the performance of the string matching using the Comments workflow against the results from the Lithology Code workflow. From the 3,074 unique records, we use a total of 1,200 samples for the confusion matrices. The reason for this difference is the limitation of building a confusion matrix wherein both workflows look at the same classes. Each row of the matrix represents the matched lithology from the Comments workflow while each column represents the matched lithology from the Lithology Code workflow. The diagonal elements represent the count for which the Comments workflow class is equal to the Lithology Code workflow. The offdiagonal elements are those that are misclassified by the Comments workflow. The higher the diagonal values of the confusion matrix the better, indicating many correct matches. The confusion matrices show normalisation by class support size. This kind of normalisation addresses the class imbalance and allow better visual interpretation of which class is being misclassified. The color of the cell represents the normalised count of the records to address the uneven distribution of records across different classes.

Relying on one metric to assess the matching can be misleading, therefore, we would like to use a couple of metrics: accuracy, precision, recall and F1 score. Accuracy sums the true positives and true negatives and puts this number in the contrast of all matches:

$$
\text { Accuracy }=\frac{\text { True Positive }+ \text { True Negative }}{\text { Positive }+ \text { Negative }}
$$

Precision is a useful metric in cases where false positives are a higher concern than false negatives. The precision of the matching is the true positives divided by the sum of the true positives and false positives. The precision measures the fraction of correctly classified are positive:

$$
\text { Precision }=\frac{\text { True Positive }}{\text { True Positive }+ \text { False Positive }}
$$

Recall is a useful metric in cases where false negatives trumps false positives. It is the percentage of total relevant results correctly classified while precision is the percentage relevant results. It is computed as: 


$$
\text { Recall }=\frac{\text { True Positive }}{\text { True Positive }+ \text { False Negative }}
$$

F1-score is a combined metric of precision and recall. It takes their harmonic mean, thus it is maximum when precision is equal to recall. However, the interpretability of the F1-score is poor. Its formula is written as:

$$
\text { Matching F1 Score }=\frac{2}{\frac{1}{\text { Recall }}+\frac{1}{\text { Precision }}}
$$

\subsection{Structure and Texture}

While geological structures are not lithologies, they are sometimes described in lithological logs (Fig 11). Structures common in the YSGB area are faults and veins. Figure 11 shows the confusion matrix for the structures and textures. The vertical axis represents the matches from the Lithology Code workflow while the horizontal axis for the results from the Comments workflow. We consider a dataset of 52 unique records where we are trying to assess if the Comments workflow results to the same classification as the Lithology Code workflow. Figure 11 shows that there are 6 records classified as "fault" and 46 records as "vein". When looking at the classification of "faults" we can say that there are 2 records that are true positives. 46 records are true negative pairs, as in this $2 \times 2$ matrix, if it is not a "fault", it is a "vein". True negatives together with true positives are the Exact Matches and suggests that the Comments workflow identified it correctly. To have a better look at the parts that were not classified correctly we look at the false positives and false negatives. False positives represent the number of records classified as "fault" but based on the Lithology Code workflow are not. In this case, there are no false positive values. False negatives represent number of records classified as "vein" but are actually "faults" based on the Lithology Code workflow.

A total of 48 Exact Matches were noted, 46 records of which are "veins" and 2 records are "faults". This can be surmised by looking into the diagonal cells. The rest of the "veins" (4 records) are Related Matches as "faults". They are considered Related Matches as faults and veins tend to coexist in nature. In addition, faults often occur as fault zones, with infill clay or silica vein sulphides which are described in the comments that then obscures the classification. These structure-related lithological descriptions can be used as proxies in further geological studies. 


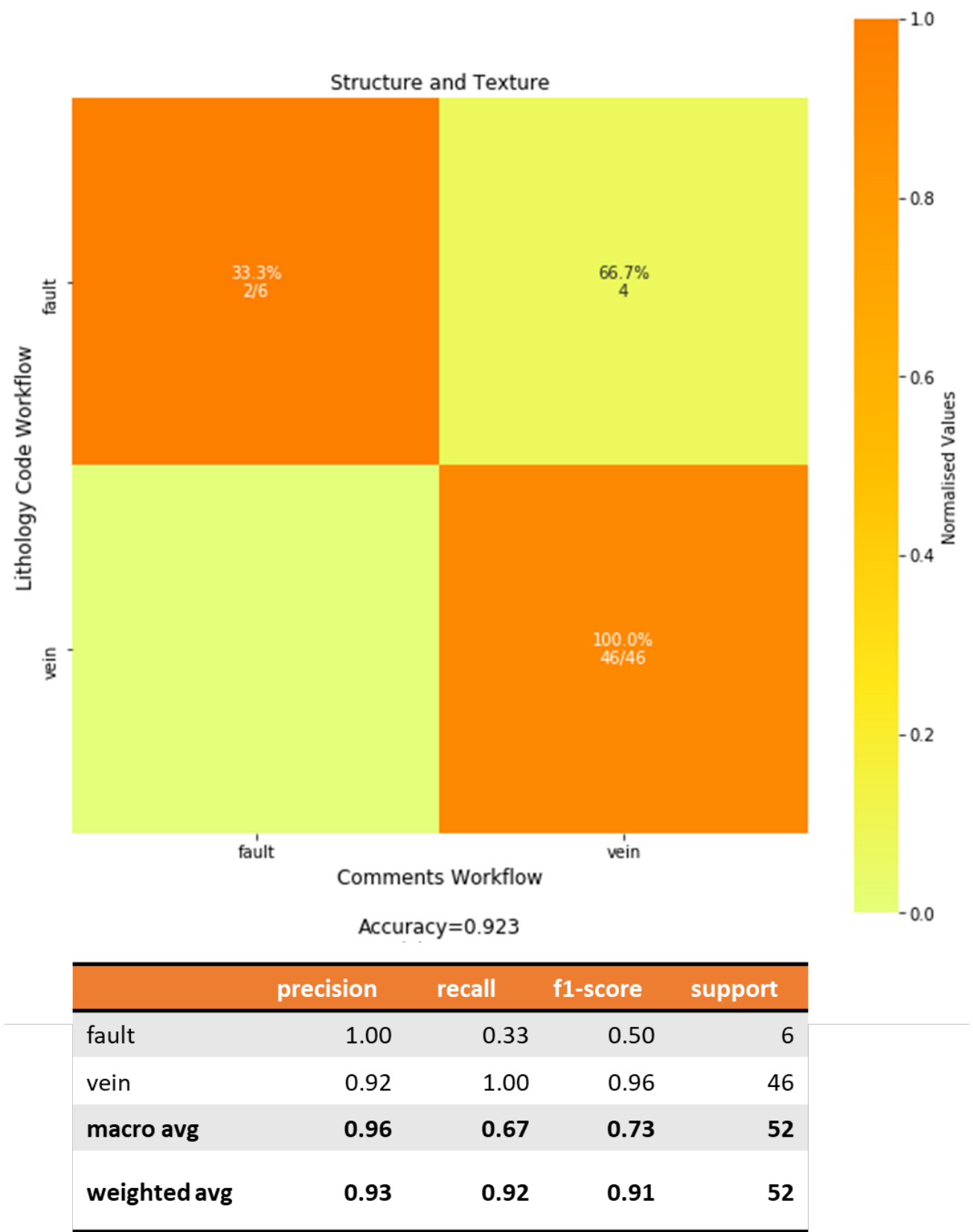

Figure 11. Confusion matrix for structure and texture comparing the fuzzy string matching results from the Lithology_Code workflow (vertical axis) and Comments workflow (horizontal axis). The heatmap shows the values normalised to the support size to address the imbalance between classes. The values shown in the cells indicate the number of samples classified for the class. Empty cells indicate zero samples. The Structures and Texture Li thology_Group had an accuracy of $92.3 \%$ across 52 samples, 46 for veins and 6 for faults.

\subsection{Igneous Rocks}

The confusion matrix for igneous rocks considers a dataset of 218 unique records (Fig 12). Dealing with a larger matrix is not as straight-forward as the previous matrix. When looking at the classification of a single lithology, the true positives are where both axes refer to the same class. For example, for "basalt" there are 15 records of true positives which correspond to the Exact 
Matches. The false positives are the sum of all the other entries along the corresponding vertical axis and the false negatives are the sum of all the entries along the corresponding horizontal axis. The sum of all the other cells represent the true negatives. For "basalt", there are 15 true positives, 13, false positives, 15 false negatives and 175 true negatives. This results to $54 \%$ 710 classification precision for "basalt".

This statistic is helpful in quantifying the performance of the classification. However, what it does not capture is the semantic and hierarchical relationship of the false negative pairs. As shown in Figure 12, 3 records were classified as "komatiite" and 12 records were classified as "mafic". The "komatiite" matches are a result of when the comments describe the basalts as

715 "komatiitic basalts". This can be considered as a Related Match. The 12 records which were classified as "mafic: are considered "Broader Match". For the false positive values, the "mafic" records are Narrower Matches while the "dolerite" is a Related Match. These quantitative assessment of the matches show us that although the matching is not perfect, the context of the misclassification is not severe.

720 "Dolerite" is the most common igneous rock matched. This could be attributed to the sampling bias towards dolerite as it is often targeted by drilling as they are used as targeting criteria for gold mineralisation (Groves et al., 2000). Given that dolerites can be described by their mafic component or be confused as gabbro when weathered, the descriptions contain strings "mafic" and "gabbro" which explain Close and Broader Matches. Gabbros are also common in the YSGB. Some of the "gabbros" were classified as "mafic" in the Comments Detai 1ed_Lithology. This is another example of a Broader Match. However,

725 it is important to note that although it is not an Exact Match, a Broader Match can be useful in geological studies relating to rock composition as gabbros are members of mafic rocks. $40 \%$ of the igneous rock that were mismatched at the Detailed_Li thology level were Broader Matches (matches correctly at Li thology_Group). 
https://doi.org/10.5194/gmd-2020-391

Preprint. Discussion started: 4 February 2021

(c) Author(s) 2021. CC BY 4.0 License.

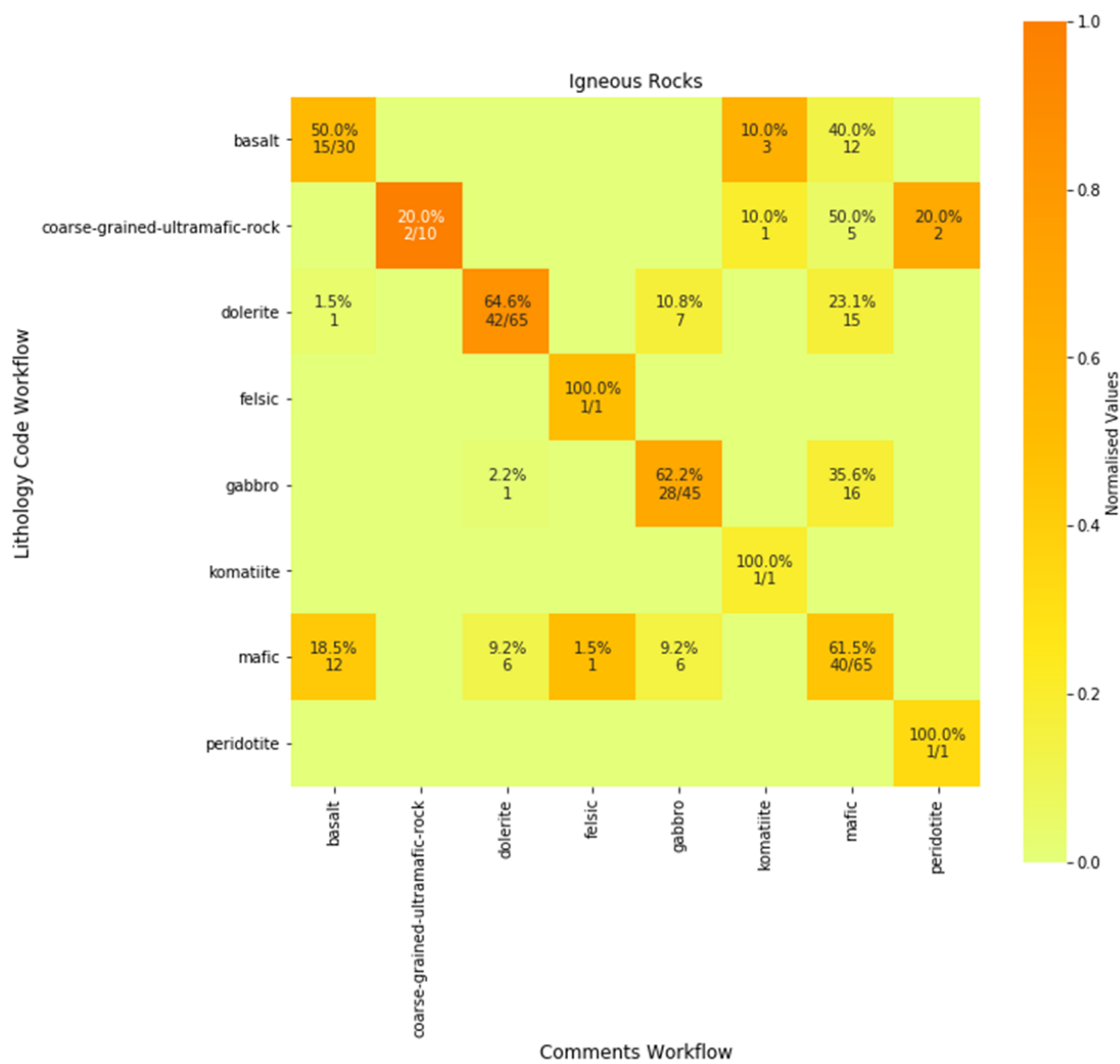

\begin{tabular}{|c|c|c|c|c|}
\hline & precision & recall & f1-score & support \\
\hline basalt & 0.54 & 0.50 & 0.52 & 30 \\
\hline $\begin{array}{l}\text { coarse-grained- } \\
\text { ultramafic-rock }\end{array}$ & 1.00 & 0.20 & 0.33 & 10 \\
\hline dolerite & 0.86 & 0.65 & 0.74 & 65 \\
\hline felsic & 0.50 & 1.00 & 0.67 & 1 \\
\hline gabbro & 0.68 & 0.62 & 0.65 & 45 \\
\hline komatiite & 0.20 & 1.00 & 0.33 & 1 \\
\hline mafic & 0.45 & 0.62 & 0.52 & 65 \\
\hline peridotite & 0.33 & 1.00 & 0.50 & 1 \\
\hline macro avg & 0.57 & 0.70 & 0.53 & 218 \\
\hline weighted avg & 0.66 & 0.60 & 0.60 & 218 \\
\hline
\end{tabular}

Figure 12. Confusion matrix for igneous rocks comparing the fuzzy string matching results from the Lithology_Code workflow 730 (vertical axis) and Comments workflow (horizontal axis). The heatmap shows the values normalised to the support size to address the imbalance between classes. The values shown in the cells indicate the number of samples classified for the class. Empty cells indicate zero samples. The accuracy is $59.6 \%$, with a weighted average precision of $66 \%$ and recall of $60 \%$. These results were taken 
https://doi.org/10.5194/gmd-2020-391

Preprint. Discussion started: 4 February 2021

(c) Author(s) 2021. CC BY 4.0 License.

from a subset of 218 samples across 8 classes. "Coarse-grained-ultramafic-rock" has a precision of 1 that implies there are no False Positives.

$735 \quad 5.3$ Sedimentary Rocks

The largest Li thology_Group of the lithological entries relates to sedimentary rocks (800 entries) (Fig 13). 457 of the 800 entries are true positive classification of mudstones. Mudstones are common as shale beds. Mudstones resulted in Related Matches with "chert" and "ironstone". The misclassification occurs when the logs describe intervals wherein the mudstone occurs together and is intercalated with these lithologies. A few mudstones (17) are matched as sandstone due to textural and 740 grain-size descriptors (Close Match). 48\% of the cherts are resulted in Exact Matches. 39 records of cherts resulted in Failed Matches as their Detailed_Lithogy level matched with "banded iron formation", it occurs when intercalated together such as "cherts with BIF" or as include string descriptors such as "BIF-fy". 
https://doi.org/10.5194/gmd-2020-391

Preprint. Discussion started: 4 February 2021

(c) Author(s) 2021. CC BY 4.0 License.

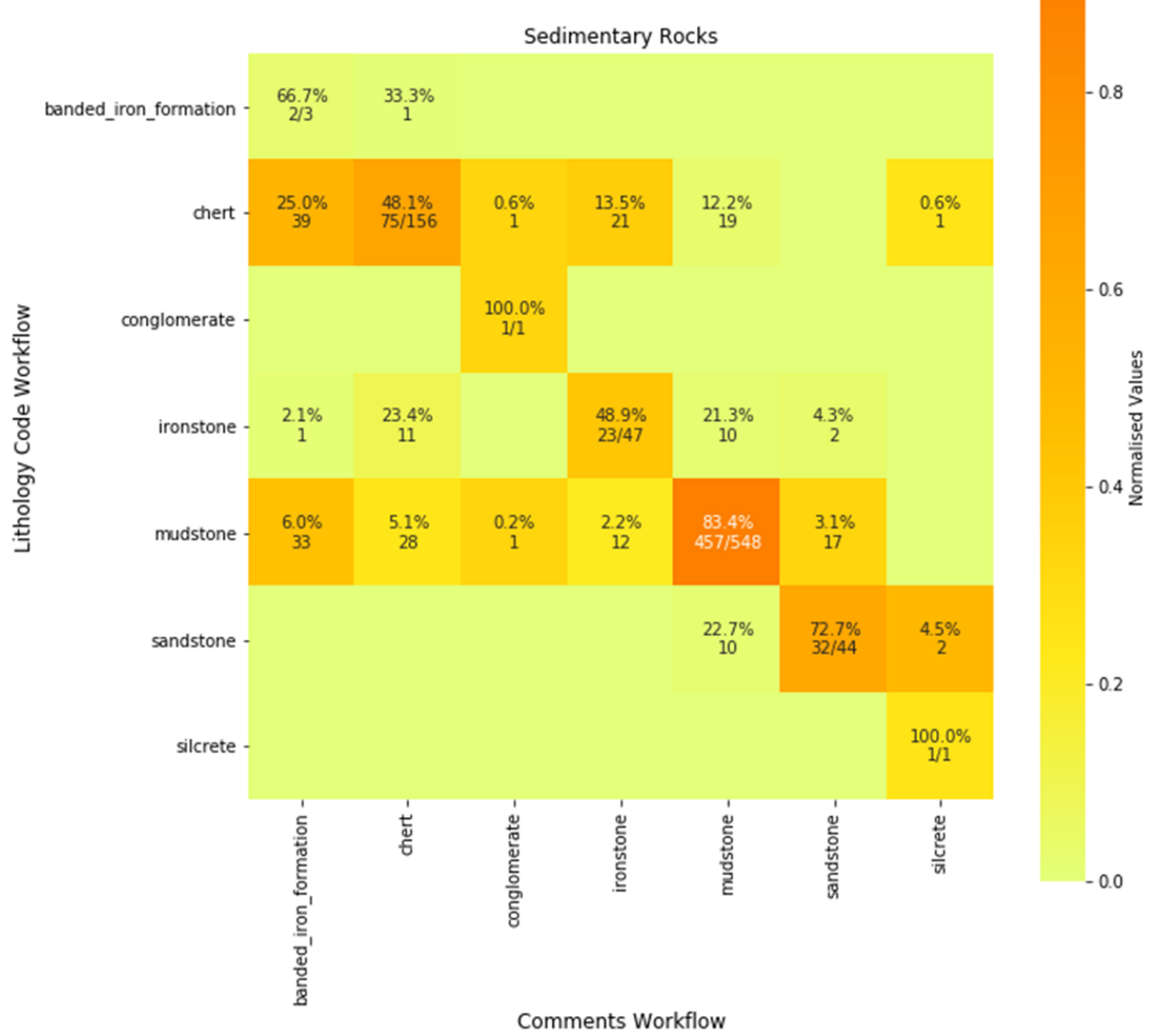

Accuracy $=0.739$

\begin{tabular}{rrrrr}
\hline & precision & recall & f1-score & support \\
\hline banded_iron_formation & 0.03 & 0.67 & 0.05 & 3 \\
chert & 0.65 & 0.48 & 0.55 & 156 \\
\hline conglomerate & 0.33 & 1.00 & 0.50 & 1 \\
ironstone & 0.41 & 0.49 & 0.45 & 47 \\
mudstone & 0.92 & 0.83 & 0.88 & 548 \\
sandstone & 0.63 & 0.73 & 0.67 & 44 \\
silcrete & 0.25 & 1.00 & 0.40 & 1 \\
macro avg & 0.46 & 0.74 & 0.50 & 800 \\
\hline weighted avg & 0.82 & 0.74 & 0.77 & 800 \\
\hline
\end{tabular}

Figure 13. Confusion matrix for sedimentary rocks comparing the fuzzy string matching results from the Lithology Code workflow 745 (vertical axis) and Comments workflow (horizontal axis). The heatmap shows the values normalised to the support size to address the imbalance between classes. The values shown in the cells indicate the number of samples classified for the class. Empty cells indicate zero samples. The accuracy is $73.9 \%$, with a weighted average precision of $82 \%$ and recall of $74 \%$. These results were taken from a subset of 800 samples across 7 classes. 
Out of a total of 61 metamorphic rock entries, 60 were matched correctly (Fig 14). Most of these were "schists" as the YSGB area is rich in talc-carbonate schists. The Company_Lithology entry "amphibolite mica schist" which was matched as "amphibolite" matches as "schist" in the Comments workflow. This is considered a Related Match.

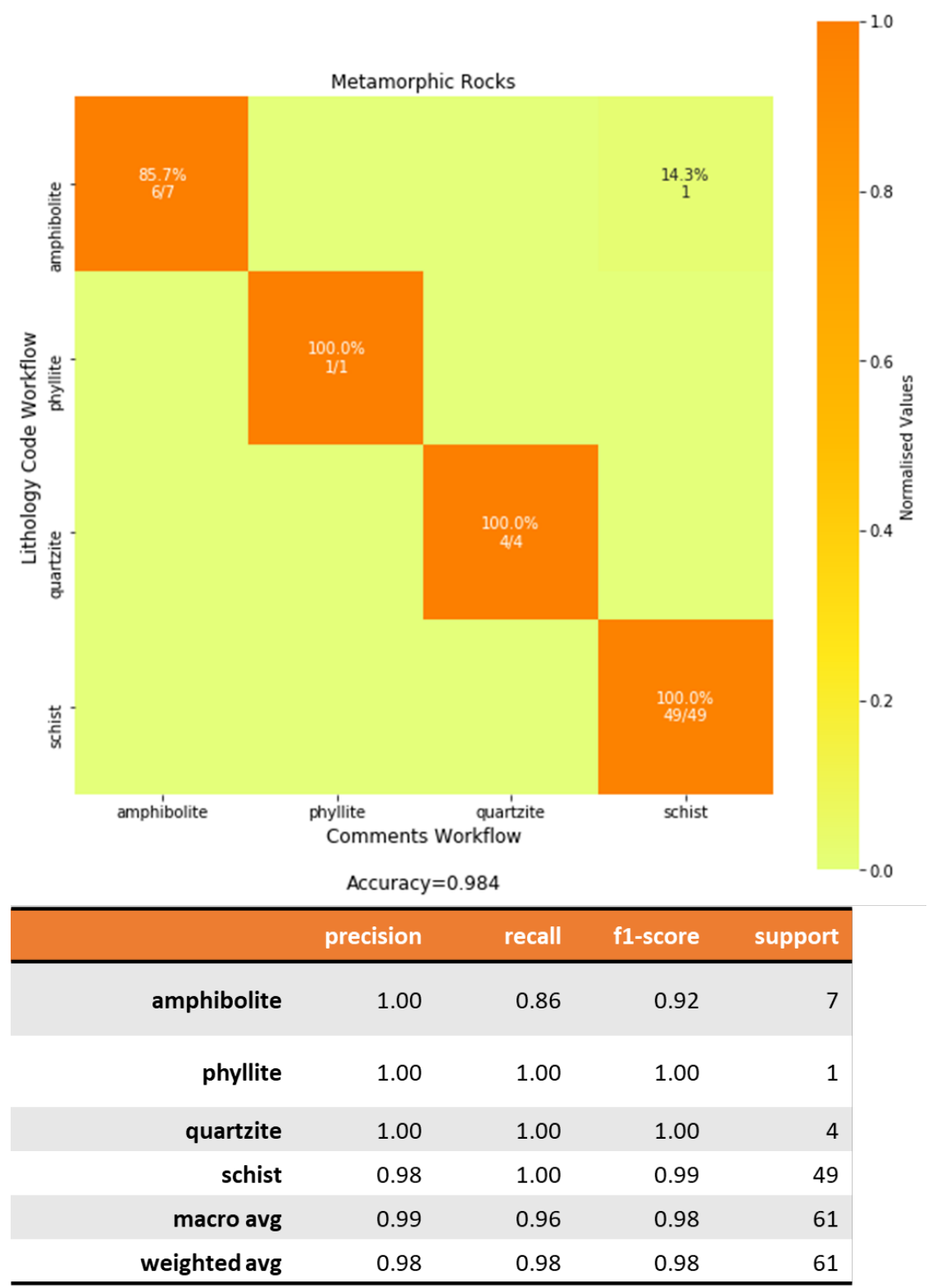

Figure 14. Confusion matrix for metamorphic rocks comparing the fuzzy string matching results from the Lithology_Code workflow (vertical axis) and Comments workflow (horizontal axis). The heatmap shows the values normalised to the support size to address the imbalance between classes. The values shown in the cells indicate the number of samples classified for the class. Empty cells indicate zero samples. The accuracy is $98.4 \%$, with a weighted average precision of $98 \%$ and recall of $98 \%$. These results were taken from a subset of 61 samples across 4 classes. 
https://doi.org/10.5194/gmd-2020-391

Preprint. Discussion started: 4 February 2021

(c) Author(s) 2021. CC BY 4.0 License.

(c) (i)

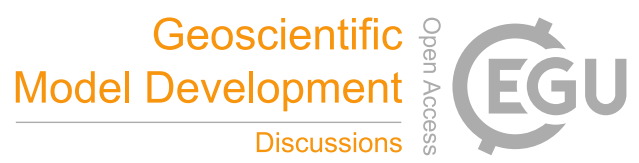

\subsection{Surficial Rocks}

Fuzzy string matching accuracy of surficial rocks scored a $45 \%$ on a total of 69 entries (Fig 15). Saprolites were matched as saprolite (Exact Match), rock (Failed Match) and saprock (Close Match). In instances where saprock was inputted as "sap rock", it results to a failed match as "rock". "Soil" is commonly used in logs to refer to the first intercept of highly weathered, clay-rich and unidentifiable intercept. "Soil" was classified with the highest variability of terms: "soil" (Exact Match), "rock"

(Failed Match), “duricrust" (Close Match), "colluvium” (Related Match) and "calcrete" (Close Match). "Laterite” was matched to "colluvium" (Related Match), "duricrust" (Close Match) and "lag" (Close Match). "Lag" generally matches with "colluvium: (Related Match). However, when described in the comments, it can be associated with its protolith which results into a Failed Match as "rock".

770 


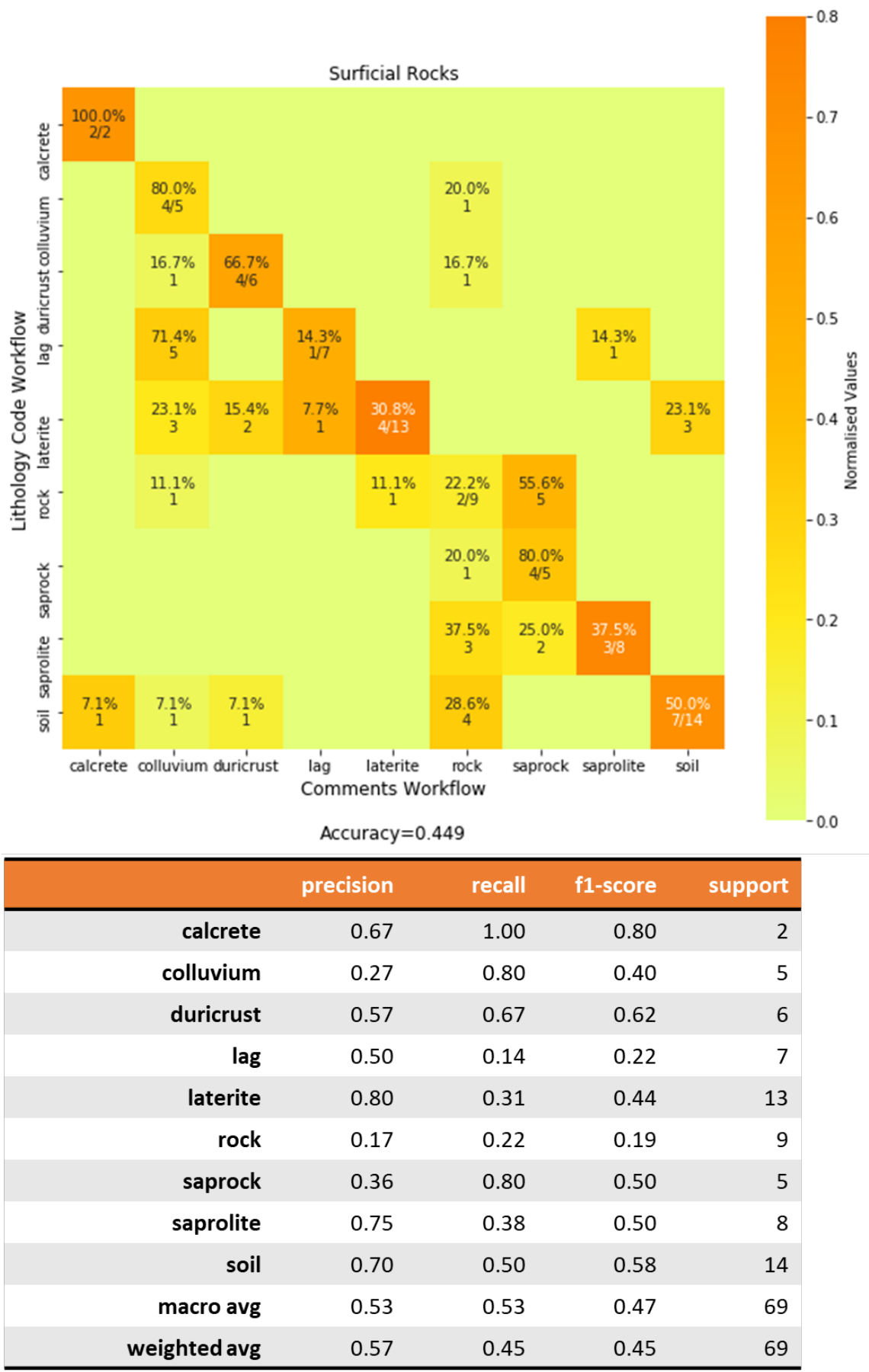

Figure 15. Confusion matrix for surficial comparing the fuzzy string matching results from the Lithology_Code workflow (vertical

axis) and Comments workflow (horizontal axis). The heatmap shows the values normalised to the support size to address the imbalance between classes. The values shown in the cells indicate the number of samples classified for the class. Empty cells indicate zero samples. The accuracy is $44.9 \%$, with a weighted average precision of $57 \%$ and recall of $45 \%$. These results were taken from a subset of 69 samples across 9 classes. 


\section{Discussion}

\subsection{Data Extraction}

dh2loop supports data extraction of collar, survey and lithology interval tables. The main consideration in the data extraction was that the data retrieved was complete, relevant and useful. We would rather throw erroneous or questionable data out and have the rest with a high level of confidence, than the other way around. $93 \%$ of the available collar data in the area was extracted successfully. This can be improved by implementing alternative ways for retrieving RL and MaxDepth values. For example, if no RL values are fetched from the database, it could be fetched from open-source digital terrain models (DTM) and/or SRTM (Shuttle Radar Topography Mission). As for missing MaxDepth values, the maximum ToDepth values in the survey and/or interval tables could be used.

The survey extraction rate of $86 \%$ was fairly good. dh2loop ensures that the Azimuth and Dip values are sensible measurements before including them into the extracted output file. An improvement that could be implemented is to run an assessment on the deflection angles for each drill hole and flag intervals with unrealistic deflection angles.

The lithology extraction using the Lithology Code workflow shows that the bottle neck to its extraction rate is the extensiveness of the Lithology Code thesaurus. Since the thesaurus did not have the information for all companies in the area, only $34 \%$ of the available information was retrieved. The extraction results for the Comments workflow cannot be compared with the Lithology Code workflow as only the intersection of both workflows was considered in this study.

\subsection{Thesauri}

dh2loop provides the user with 9 thesauri that deal with the extraction of collar, survey and lithology interval tables. For extraction of other properties, such as downhole alteration, geochemistry, mineralogy and structures, at least one thesaurus is needed for each attribute we would like to export. These thesauri are built manually by inspecting all the terminologies available in the database. Although, creating them can be tedious, updating an existing thesaurus is as simple as adding and/or removing a word to the list. There are many other properties available in the database that could be exploited using the existing methodology, thus there is an incentive in finding a way to improve the methodology of building these thesauri. Analysis on the syntax of the existing thesauri may help in automating creation of other thesauri.

The Hierarchical Lithology thesaurus puts equal weight on each of the entries in the thesaurus. Knowing the geology in a user's area, the matching can be improved by adding more weight to prevalent lithologies through adding a bonus score.

\subsection{Assessment of String Matching Results}

The string matching results highlights that geological drill core logging is prone to human error and bias, and result to incorrect

logs. Sometimes even if the data is available and correct, it is not in format that can be directly extracted. For example, the Comment field/s are filled with a string description such as "same as above" and "-do-“. Currently, for this case, dh2loop returns without a match. In the future, we could be able to search through the previous entries to retrieve the correct lithology. Furthermore, the code does not handle and check for inconsistencies in the logs. It only addresses the inconsistencies in nomenclature and not the logging itself. The string matching misclassification results illustrate that importance in the

815 consistency and level of detail being put into logging and identifies differences in convention or uncoordinated logging among geologists. dh2loop provides a notebook that demonstrates using striplog to improve the consistency of the logs through data pruning and annealing. In the future, the geochemical compositions can be used to counter check and lithology assigned to the interval. 

to a higher matching rate, $86 \%$ of the extracted data is successfully matched. Comparing this subset to the Comments workflow, the matching rate is much lower at $16 \%$. This shows that the Lithology Code workflow, while potentially tedious, results into a higher percentage of successful matches. However, if we are considering a regional study involving multiple companies and drilling campaigns, building thesauri can be time-consuming depending on the size of the region being studied, number of attributes of interest, number of companies and drilling campaigns. This could range from a couple of hours to months. It can also be tedious as it involves inputting errors and inconsistencies as well as exhausting all permutations for decision-tree based logging systems

Comment matching provides a quicker way to standardize and classify rocks. The comprehensive clean-up dictionary allows assists in improving the matching accuracy. Given the context that we are dealing with legacy data, an extraction rate of $16 \%$ from the Comments is not bad at all. With minimal effort, we obtain additional geological data wherein, although of a smaller percentage (31\% of Exact Matches) but with reasonably high confidence in its quality. It is important to note that most of the time Failed Matches are not a result of the limitations of the algorithm but of the information being fed itself. Inconsistent logs (Company_Li tho data is different from Comment) usually occur when:

1. The logs were post-processed and correlated with the rest of the hole or neighbouring drill holes and changes were made to the Company_Litho but none on the Comments field.

2. The Comments would have more level of detail than the Company_Li tho. In this case, we may get a lithology at Lithology_Subgroup from the Lithology Code workflow and a Detailed_Lithology from the Comments workflow.

3. The Company_Li tho would have more level of detail than the Comments

4. Comments contains the description of the whole intercept, which could include a contact of two lithologies or intercalating lithologies.

From the results of the confusion matrix (Sect. 5), some rock groups are more sensitive to these inconsistencies than others.

There is higher confidence in the classification of structures and textures and metamorphic rocks. The user should be more careful when dealing with igneous, sedimentary and surficial rocks. They are more difficult to classify as the way they are described are highly variable between different geologists. For structure-related lithological descriptions the small number of misclassifications occur where faults, veins and fillings coexist. For metamorphic rocks, entries like "mica amphibolite schist" can cause Broader Matches with the confusion of whether to classify it as "amphibolite" or "schist". "Schist" is a textural term of medium grade metamorphic rock with a medium to coarse-grained foliation defined by micas while "amphibolite" is a compositional term representing a granular metamorphic rock which mainly consists of hornblende and plagioclase. One should be wary about these possibilities as they may impact the interpretation of the geology in the area. For sedimentary rocks, the lack of a standard syntax as to how comments are recorded impacts the classification. Descriptions of intercalated lithologies or presence of major and minor lithology can result to Failed Matches. Igneous rocks perform fairly well, most of what is not captured as Exact Matches are captured at least as Broader Matches. These are usually related to either an inconsistent level of detail between the fields or rock types used as descriptors ("komatiitic", "andesitic", basaltic").

Low matching accuracy in surficial rocks can be attributed to the lack of universally agreed terminology for: deeply weathered regolith; poorly-defined and misapplied surficial rock nomenclature; wide range and variation of materials within the regolith and; difficulty in bulk mineral identification from macroscopic samples. Furthermore, since the degree of weathering of minerals generally increases from the bottom to the top of in-situ weathering profiles, the intermixing of strongly weathered 
and less weathered grains may cause confusion (Cockbain, 2002). Ubiquitous, highly variable and less interesting lithologies also cause mismatches. An example of this is "soil". Soils are technically are not rocks but is commonly used in logs to refer to the first intercept of the regolith or to describe highly weathered, clay-rich and unidentifiable intercept. Soils vary in character from thin, coarse-grained, poorly differentiated lithosols to thick, well-differentiated silt and clay-rich soils. Soils were classified with the highest variability of terms: "soil", "rock", "duricrust", "colluvium" and "calcrete". There are also certain lithologies with ambiguous nomenclature conventions, like "laterite", "duricrust", "lag". Some geologists use laterite to refer to the whole lateritic profile (ferruginous zone, mottled zone, and saprolite) while others to refer to the ferruginous zone (Eggleton, 2001). Ironcrust, duricrust, lateritic gravels and lag are commonly used interchangeably. Duricrust and ironcrust are terms to describe ferruginous indurated accumulations at or just below the surface. The difference in usage of the term laterite and the interchangeability of duricrust and lag explains the misclassification of "laterite" to "colluvium", "duricrust" and "lag". Another example is "saprolite" and "saprock". They are ambiguous terminologies as they both represent the lower horizons of lateritic weathering profiles, with saprolites having more than $20 \%$ of weatherable minerals altered and saprock having less than $20 \%$ of the weatherable minerals being altered (Eggleton, 2001). This arbitrary limit makes the terminology used in the logs easily interchangeable, thus affecting the Detai 1 ed_Li thology matching.

Ideally, a combination of the Lithology Code and Comments workflow should result in a more robust classification. This will also allow the user to have a better look at the result of both workflows and decide what is appropriate for one's purpose.

\subsection{Value of the Lithological Information Extracted for Multiscale Analyses}

The dh2loop lithology export provides a standardized lithological log across different drilling campaigns. This information can readily imported into 3D visualization and modelling software. This allows for drill hole data to be incorporated into 3D modelling, providing better subsurface constraints, especially at a regional scale. It also allows the user to decide on the lithological resolution necessary for their purpose. It provides a three-level hierarchical scheme: Detai 1ed_Li thology, Lithology_Subgroup and Lithology_Group that can be used as an input to multiscale geological modelling. dh2loop can be improved by correlating the these lithologies to their corresponding stratigraphic formations. Having the spatial extents of the different geological formations and their lithological assemblages (GSWA Explanatory Notes System) as well as a couple of stratigraphic drill holes, it may be possible to infer the corresponding stratigraphic formation.

\section{7 dh2loop Functions and Notebooks}

The dh2loop library supports a workflow that extracts, processes and classifies lithological logs (Appendix A3). This library was built to extract drill hole logs from the WAMEX database. The assumptions made in the entire workflow attempts to replicate the thought process of a geologist performing the data extraction, data quality checks and lithological log classification manually. However, it can be adapted for other geological relational databases or from other table formats. An example using comma separated values tables (CSVs) is shown in the notebook: Exporting and Text Parsing of drill hole Data Demo.

In addition to the data extraction, downhole desurveying and lithological matching functions discussed, dh2loop also provides functionalities and a notebook demonstrating harmonization of drill hole data. This is useful for combining and correlating drill hole exports of different properties such as lithology, assays and alteration. It is also possible to export this information in Visualization Toolkit format (.VTK). It also provides a notebook that demonstrates the application of lasio and striplog on

900 dh2loop interval table exports. WAMEX reports can also be interactively downloaded through a notebook provided in the package. 
https://doi.org/10.5194/gmd-2020-391

Preprint. Discussion started: 4 February 2021

(c) Author(s) 2021. CC BY 4.0 License.

(c) (i)

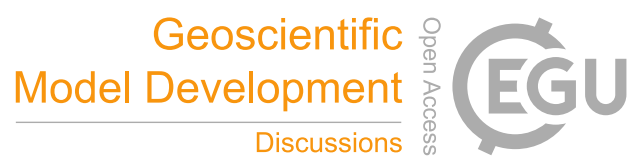

\section{Conclusions}

The dh2loop library is an open-source library that extracts geological information from a legacy drill hole database. This workflow has the following advantages:

905

1. Maximizes the decades of legacy geoscientific data available

2. Gains better subsurface characterization, where data is available

3. Standardizes geological logs across different drilling campaigns, a necessary but typically time-consuming and errorprone activity

4. Provides s set of complementary thesauri that can easily be updated

5. Provides additional subsurface constraints which are critical for $3 \mathrm{D}$ geological modelling

6. Implements a hierarchical classification scheme that can be used as an input to multiscale geological modelling

7. Classification results can also be used as a tool to improve future geological logging works by revealing common errors and sources of inconsistencies 
https://doi.org/10.5194/gmd-2020-391

Preprint. Discussion started: 4 February 2021

(c) Author(s) 2021. CC BY 4.0 License.

(c) (i)

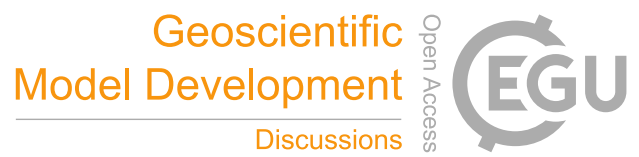

915 Code and Data Availability

dh2loop is a free, open-source python library licensed under the MIT License. It is hosted on the GitHub repository https://github.com/Loop3D/dh2loop and can be cited as http://doi.org/10.5281/zenodo.4043568.

\section{Author Contribution}

M. Jessell contributed the original idea, which was further developed by R. Joshi. K. Madaiah developed the code. M. Jessell,

920 M. Lindsay, G. Pirot provided guidance and direction in the research. R. Joshi prepared the manuscript with contributions from all co-authors. Lastly, M. Jessell supervised the entire process.

\section{Acknowledgements}

The research was carried out while the first author was supported in receipt of Scholarship for International Research Fees (Australian Government Research Training Program Scholarship) and Automated 3D Geology Modelling PhD Scholarship (University Postgraduate Award) at the University of Western Australia. The work has been supported by the Mineral Exploration Cooperative Research Centre whose activities are funded by the Australian Government's Cooperative Research Centre Program. This is MinEx CRC Document 2020/***. This work was also done with the Loop Consortium (http://loop3d.org) as part of an international effort to found a new open-source platform to build the next generation of 3D geological modelling tools. Mark Lindsay is funded by ARC Discovery DE190100431. We would also like to acknowledge Tim Ivanic for his inputs on the geology of the Yalgoo-Singleton greenstone belt. 
https://doi.org/10.5194/gmd-2020-391

Preprint. Discussion started: 4 February 2021

(c) Author(s) 2021. CC BY 4.0 License.

Appendix A: dh2loop package information

\section{A1 Installation}

Installing dh2loop can be done by cloning the GitHub repository with $\$$ git clone https://github.com/Loop3D/dh2loop.git and then manually installing it by running the python setup script in the repository: \$ python setup.py install

\section{A2 Documentation}

dh2loop's documentation provides a general overview over the library and multiple in-depth tutorials. The tutorials are provided as Jupyter Notebooks, which will provide the convenient combination of documentation and executable script blocks in one document. The notebooks are part of the repository and located in the notebooks folder. See http://jupyter.org/ for more information on installing and running Jupyter Notebooks.

\section{A3 Jupyter notebooks}

Jupyter notebooks are provided as part of the online documentation. These notebooks can be executed in a local python environment (if the required dependencies are correctly installed). In addition, static versions of the notebooks can currently be inspected directly on the github repository web page or through the use of nbviewer.

1. WAMEX Interactive report downloads (https://github.com/Loop3D/dh2loop/blob/master/notebooks/0_WAMEX_Downloads_Interactive.ipynb)

2. Exporting and text parsing of drill hole data from PostgreSQL database (https://github.com/Loop3D/dh2loop/blob/master/notebooks/1_Exporting and Text_Parsing_of_Drillhole_Data_Fr om_PostgreSQL.ipynb)

3. Exporting and Text Parsing of drill hole Data Demo (https://github.com/Loop3D/dh2loop/blob/master/notebooks/2_Exporting_and Text_Parsing_of Drillhole_Data_D emo.ipynb)

4. Harmonizing drill hole data (https://github.com/Loop3D/dh2loop/blob/master/notebooks/3_Harmonizing_Drillhole_Data.ipynb) 
https://doi.org/10.5194/gmd-2020-391

Preprint. Discussion started: 4 February 2021

(c) Author(s) 2021. CC BY 4.0 License.

\section{Appendix B: Thesauri}

A few examples of each thesauri are shown below. Each thesauri includes alternate nomenclature and spelling. The complete thesauri are available at: https://github.com/Loop3D/dh2loop/blob/master/thesauri/

\section{B1 Drill hole Collar Elevation}

1. "'"'RL"'"'

2. ADJ_RL

3. Adjusted_RL

4. AMG_mRL

5. Approx RL

6. Arbitary_RL

7. Best_RL

8. COLL_RL

9. Collar Elevation

970

10. Collar RL

11. Collar RL (m)

12. Corrected_RL

13. DB_RL

14. DEM_RL

15. DGPS Elevation MGA94

Zone 51

16. DGPS RL

17. DTM RL
18. Elevaion

19. Elevat

20. Elevati

21. Elevatio

22. Elevation

23. elvation

985

24. Lidar_RL

25. Local RL

26. MGA RL

27. MGA_Elev

28. MGA_Elevation

990 29. MGA_RL_Z

30. MGA_Z50_RL

31. MGA94_RL

32. MINE_RL

33. $\mathrm{mRL}$

995
36.

37. Orig_Reg_RL

38. R.L

1000 39. R.L.

40. Raw_RL

41. Real RL

42. ref_mRL

43. RL

1005

44. Surveyed RL

45. UTMElev

46. UTMmRL

47. WGS84_WORLD_LL_Ca

lc_Z

1010

48. $\mathrm{z}$ RL

49. $Z(R L)$

50. ZCOLLAR_RL

51. ZMINE_RL

1015 B2 Drill hole Maximum Depth Thesaurus (https://github.com/Loop3D/dh2loop/blob/master/thesauri/thesaurus collar_maxdepth.csv)

\begin{tabular}{|c|c|c|c|c|c|}
\hline & 1. "'"'DEPTH"'"" & & 16. Drilled_Depth & & 31. MAX DEPTH \\
\hline & 2. "Depth & & 17. End of hole depth & & 32. max_depth (m) \\
\hline & 3. "'"'Final & & 18. END_DEPTH & & 33. Max_Depth m \\
\hline 1020 & 4. AC Depth & 1035 & 19. EOH Depth & 1050 & 34. Maximum Depth \\
\hline & 5. Actual Depth & & 20. EOH Depth (Metres) & & 35. T_depth \\
\hline & 6. DD_Depth & & 21. F/Depth & & 36. TD \\
\hline & 7. DDH_Depth & & 22. F/Depth(m) & & 37. toatl_depth \\
\hline & 8. Depth & & 23. F_Depth & & 38. TOT DEPTH \\
\hline 1025 & 9. Depth $\mathrm{m}$ & 1040 & 24. FIN_DEPTH & 1055 & 39. TOT_DEPTH_M \\
\hline & 10. DEPTH (m) & & 25. Final Depth & & 40. Total Depth \\
\hline & 11. Depth (EOH) & & 26. Final Depth (m) & & 41. Total Depth (m) \\
\hline & 12. Depth (metres) & & 27. Final_dpth & & 42. Total Depth Drilled $\mathrm{m}$ \\
\hline & 13. Depth_D & & 28. Finl_Depth & & 43. Total Depth M \\
\hline 1030 & 14. Depth_DD & 1045 & 29. НDEPTH & 1060 & 44. Total Hole Depth \\
\hline & 15. Drill Depth & & 30. Hole depth & & \\
\hline
\end{tabular}


https://doi.org/10.5194/gmd-2020-391

Preprint. Discussion started: 4 February 2021

(c) Author(s) 2021. CC BY 4.0 License.

B3 Drill hole Survey Azimuth Thesaurus

(https://github.com/Loop3D/dh2loop/blob/master/thesauri/thesaurus survey azimuth.csv )

\begin{tabular}{|c|c|c|c|c|c|}
\hline & 1. AMG AZIMUTH & 1085 & 22. Azimuth Local & & 43. Magnetic AZI \\
\hline \multirow[t]{5}{*}{1065} & 2. AMG_azim & & 23. Azimuth Mag & & 44. MGA AZI \\
\hline & 3. AMGAZM & & 24. Azimuth(T) & & 45. MGA Azimuth \\
\hline & 4. Aximuth & & 25. AzLoc & & 46. MGA94_Az \\
\hline & 5. Aximuth_gyro & & 26. GDA_Az & 1110 & 47. NAT_Azimuth \\
\hline & 6. $\mathrm{AZ}$ & 1090 & 27. GILBEYS AZI & & 48. Nominal Az \\
\hline \multirow[t]{5}{*}{1070} & 7. Az_AMG & & 28. GRID AZI & & 49. Nominal AZI \\
\hline & 8. Az_grid & & 29. GRID_AZ & & 50. Orig AZI \\
\hline & 9. AZ_LOCAL & & 30. GridAzim & & 51. Orig Azimuth \\
\hline & 10. AZ_Mag & & 31. LOCAL AZIMUTH & 1115 & 52. Orig_Azim \\
\hline & 11. AZ_MINE & 1095 & 32. Local_Az & & 53. ORIG_AZIMU \\
\hline \multirow[t]{5}{*}{1075} & 12. AZI GRID & & 33. Local_Azi & & 54. Project_Azim \\
\hline & 13. $\mathrm{AZI}(\mathrm{T})$ & & 34. Local_Azim & & 55. Ref. AZI \\
\hline & 14. Azi_Mag & & 35. LOCALAZID & & 56. ref_azim \\
\hline & 15. AZI_MGA & & 36. LocAzim & 1120 & 57. REG_AZIM \\
\hline & 16. AZIM & 1100 & 37. LOCAZM & & 58. UTM_Az \\
\hline \multirow[t]{5}{*}{1080} & 17. Azim mag & & 38. Mag_Az & & 59. UTM_Azi \\
\hline & 18. Azim_AMG & & 39. Mag_Azim & & 60. UTM_Azimuth \\
\hline & 19. Azim_Local & & 40. Mag_Azimu & & 61. WMC AZI \\
\hline & 20. Azim_M & & 41. MagAzi & & \\
\hline & 21. AZIMUTH & 1105 & 42. MAGAZM & & \\
\hline
\end{tabular}

1125

B4 Drill hole Survey Dip Thesaurus

(https://github.com/Loop3D/dh2loop/blob/master/thesauri/thesaurus survey dip.csv )

1. Dip

2. Dip (deg.)

1130

3. Dip_2

4. INC

5. Inclination

6. DIP_camera

7. Dip_gyro

1135

8. DIP_LOCAL

9. Nominal_Dip

10. DIP_Surtron

B5 Drill hole Lithology Thesaurus

(https://github.com/Loop3D/dh2loop/blob/master/thesauri/thesaurus geology lithology.csv )
1. \$Lith
2. $\%$ Maj
3. \%Maj_Lith
4. \%Major Lith

5. 1_LithCode

9. Geol

6. 1_RootCode

10. Geol Code

7. F_lithology

1150

Geol General

8. GeoCode

11. GEOL_Rock1 


\begin{tabular}{|c|c|c|c|c|c|}
\hline & 12. geol_type & & 38. Lith1_Code1 & & 64. Maj. Rock \\
\hline & 13. GEOL1 & & 39. LithCode1_A & 1205 & 65. Major Lithology \\
\hline & 14. Geological Unit & 1180 & 40. lithcode1_main & & 66. Major Rock \\
\hline \multirow[t]{5}{*}{1155} & 15. Geological_code & & 41. LithCode1_T & & 67. Major Rock Type \\
\hline & 16. GEOLOGY & & 42. LithCode1_V & & 68. Primary Lith \\
\hline & 17. Geology Code & & 43. LithCodeSy & & 69. Primary RockType \\
\hline & 18. HOST_LITH1 & & 44. Lithgen & 1210 & 70. ROCK \\
\hline & 19. Intermediate Rock Type & 1185 & 45. LithGenrl & & 71. ROCK CODE \\
\hline \multirow[t]{5}{*}{1160} & 20. lihological & & 46. Lithic_code & & 72. Rock Group \\
\hline & 21. Lilh1 & & 47. Lithlogy 1 & & 73. ROCK NAME \\
\hline & 22. lit & & 48. LithMajor1 & & 74. Rock type code \\
\hline & 23. Lit_1 & & 49. LithMin 1 & 1215 & 75. Rock Type Major \\
\hline & 24. lith & 1190 & 50. Litho & & 76. Rock Unit \\
\hline \multirow[t]{5}{*}{1165} & 25. Lith Code & & 51. LITHO $_{-} 1$ & & 77. Rock_id \\
\hline & 26. Lith 1 & & 52. Litho Code & & 78. ROCK-CODE \\
\hline & 27. Lith 1 Rock Type & & 53. Litho Type & & 79. RockLithCode \\
\hline & 28. Lith Maj & & 54. LITHO_PLOT & 1220 & 80. RockMain \\
\hline & 29. Lith Major & 1195 & 55. Lithological Unit & & 81. RockMajor \\
\hline \multirow[t]{5}{*}{1170} & 30. Lith_Cat & & 56. LITHOLOGY & & 82. Root_Code \\
\hline & 31. Lith_Codes & & 57. Lithology_rock & & 83. Root_Lith \\
\hline & 32. Lith_Maj_1 & & 58. Lithoology & & 84. Root_rock \\
\hline & 33. Lith_PrimaryCode & & 59. Main Geol Unit & 1225 & 85. Wiluna Lithology Code \\
\hline & 34. LITH_Protolith & 1200 & 60. Main Lithology & & 86. WMC ROCK Code \\
\hline \multirow[t]{3}{*}{1175} & 35. LITH_TYPE & & 61. MAJ LITH & & 87. wme_lith 1 \\
\hline & 36. Lith01 & & 62. Maj Lithcode & & \\
\hline & 37. lith-1 & & 63. Maj. Lithology & & \\
\hline
\end{tabular}

B6 Drill hole Comments Thesaurus

1. Comment

2. COMMENTS

3. D_stLITHCOMMETNS

4. Description

5. INTRCPT COMMENT

6. LITH_COMMENT

B7 Drill hole Lithology Codes Thesaurus (https://github.com/Loop3D/dh2loop/blob/master/Thesauri/thesaurus geology lithology code.csv )

\section{CompanyID $>$ Company_LithoCode $>$ Company_Litho}

1. $551>\mathrm{BIF}>$ Banded iron formation

2. $1311>$ BIF $>$ Banded iron formation

3. $551>\mathrm{CS}>$ Saprolite, undifferntiates

4. $2551>$ Cs $>$ Cambrian Sediment
5. $551>\mathrm{CSM}>$ Mafic saprolite

6. $2551>$ Csm $>$ Cambrian Sediment Limestone

7. $2551>\mathrm{Cv}>$ Cambrian Vein material

8. $2790>\mathrm{CV}>$ Colluvium 
9. $551>\mathrm{CY}>$ Clay, undifferentiated

10. $2551>\mathrm{Cy}>$ Cambrian Mylonite

1250

11. $2551>\mathrm{Hp}>$ Carboniferous Massive sulphide

12. $2790>\mathrm{HP}>$ Hardpan

13. $2551>$ Lc $>$ Oligocene Chemical Sediments

1290

14. $3053>\mathrm{Lc}>$ undiferentiated laterite clay

15. $2551>$ Ls $>$ Oligocene Sediment

1255

16. $3053>$ Ls $>$ undiferentiated laterite sand

17. $1311>\mathrm{MB}>$ Basalt

18. $2551>\mathrm{Mb}>$ Miocene Mafic Extrusive

19. $369>\mathrm{PH}>$ Phyllite

20. $2551>\mathrm{Ph}>$ Proterozoic Hornfels

1260

1265

1270

1275

1280
21. $2551>$ Qc $>$ Quaternary Chemical Sediments

22. $3053>$ Qc $>$ undifferentiated recent surficial deposit clay

23. $2551>$ Qs $>$ Quaternary Sediment

24. $3053>$ Qs $>$ undifferentiated recent surficial deposit sand

25. $551>$ QV $>$ Quartz Vein

26. $2551>$ Qv $>$ Quaternary Vein material

1305

27. $369>\mathrm{S}>$ Undifferentiated sediments

28. $3053>\mathrm{S}>$ undifferentiated sediment

29. $2551>\mathrm{Sh}>$ Silurian Hornfels

30. $3053>\mathrm{Sh}>$ shale

31. $551>\mathrm{SS}>$ Sandstone

32. $2551>$ Ss $>$ Silurian Sediment

33. $369>$ TCC $>$ Channel clays

34. $1311>$ TCC $>$ Tertiary palaeochannel clay

35. $369>$ TCS $>$ Channel sands

36. $1311>$ TCS $>$ Tertiary palaeochannel clayey sand 1315

37. $369>$ TLC $>$ Lake clays

38. $2551>$ Tlc $>$ Triassic Lamprophyre/Kimberlites Carbonatite

39. $369>$ ALL $>$ Alluvium

40. $2790>$ ALLU $>$ Alluvium

41. $2790>$ AMPH $>$ Amphibolite

42. $369>$ MAA $>$ Amphibolite

43. $369>$ MBA $>$ Basalt

1310
44. $2790>$ CALC $>$ Calcrete

45. $369>$ LCZ $>$ Calcrete

46. $11410>$ CL $>$ Clay

47. $2790>$ CLAY $>$ Clay

48. $369>$ COL $>$ COLLUVIUM

49. $2790>$ COLL $>$ Colluvium

50. $369>$ FDI $>$ Diorite

51. $2790>$ IDO $>$ Diorite

52. $3053>$ Bdo $>$ dolerite

53. $2790>$ DOLR $>$ Dolerite

54. $1311>\mathrm{MD}>$ Dolerite

55. $3053>\mathrm{Bgb}>$ gabbro

56. $2790>$ GABR $>$ Gabbro

57. $2790>$ MDG $>$ Gabbro

58. $11410>\mathrm{MG}>$ Gabbro

59. $369>$ MGA $>$ gabbro

60. $369>$ FGR $>$ Granite

61. $11410>$ GR $>$ Granite

62. $2790>$ GRAN $>$ Granite

63. $2790>$ HARD $>$ Hardpan

64. $369>\mathrm{LDH}>$ Hardpan

65. $2790>\mathrm{NMO}>$ Mottled zone

66. $2790>\mathrm{WMZ}>$ Mottled zone

67. $369>$ FPG $>$ Pegmatite

68. $2790>$ PEGM $>$ Pegmatite

69. $2790>$ QZVN $>$ Quartz Vein

70. $2790>$ VQZ $>$ Quartz Vein

71. $2790>$ FSS $>$ Sericite schist

72. $551>$ SESCH $>$ Sericite Schist

73. $2790>$ UMS $>$ Serpentinite

74. $3053>$ Us $>$ serpentinite

75. $369>\mathrm{SSH}>$ Shale

76. $369>$ LSZ $>$ Silcrete

77. $2790>$ SILC $>$ Silcrete

78. $2790>$ SLS $>$ Siltstone

79. $369>$ SSTS $>$ Siltstone

80. $369>\mathrm{M}>$ Undifferentiated Mafic Rocks

81. $2790>$ MOO $>$ Undifferentiated mafic rock 
https://doi.org/10.5194/gmd-2020-391

Preprint. Discussion started: 4 February 2021

(C) Author(s) 2021. CC BY 4.0 License.

1325 B8 Clean up dictionary (https://github.com/Loop3D/dh2loop/blob/master/thesauri/thesaurus cleanup.csv)

B9 Lithology Hierarchical Thesaurus

(https://github.com/Loop3D/dh2loop/blob/master/thesauri/thesaurus geology hierarchical.csv ) 
https://doi.org/10.5194/gmd-2020-391

Preprint. Discussion started: 4 February 2021

(c) Author(s) 2021. CC BY 4.0 License.

Appendix C:

1330 C1 Configuration file

\#Extents to query

minlong $=115.5$

$\max$ long $=118$

$\min 1$ at $=-30.5$

$1335 \max 1$ at $=-27.5$

\#src_pro,Dst_proj

src_csr $=4326$

dst_csr $=28350$

1340

\#ExportFiles

export_path=' . ./data/export_db/'

DB_Co11ar_R1_Log = export_path + 'DB_Co11ar_R1_Log.1og'

DB_Col1ar_Maxdepth_Log = export_path + 'DB_Co11ar_maxdepth_Log.1og'

1345 DB_Col1ar_Export=export_path+'DB_Col1ar_Export.csv'

DB_Survey_Export=export_path+'DB_Survey_Export.csv'

DB_Survey_Export_Calc=export_path+ 'DB_Survey_Export_Calc.csv'

CET_Litho=export_path+ 'CET_Litho.csv'

DB_Lithology_Export=export_path+'DB_Lithology_Export.csv'

1350 DB_Lithology_Export_Backup=export_path+'DB_Lithology_Export_Backup.csv'

DB_Lithology_upscaled_Export=export_path+'DB_Lithology_Upscaled_Export.csv'

Upscaled_Litho_NoDuplicates_Export = export_path+'Upscaled_Litho_NoDuplicates_Export.csv'

DB_Lithology_Export_Calc=export_path+'DB_Lithology_Export_Calc.csv'

1355

DB_Lithology_Export_VTK=export_path+'DB_Lithology_Export.vtp'

print('Default parameters 1oaded from DH2_LConfig.py:')

with open('../notebooks/DH2_LConfig.py', ' $r$ ') as myfile:

data $=$ myfile $\cdot \operatorname{read}()$

print (data)

1360 myfile.close()

print ('\nModify these parameters in the cell below') 
https://doi.org/10.5194/gmd-2020-391

Preprint. Discussion started: 4 February 2021

(c) Author(s) 2021. CC BY 4.0 License.

\section{C2 Fuzzy String Matching Pseudocode}

1365 DEFINE FUNCTION Attr_val_with_fuzzy():

Bestmatch is -1

Bestlitho is ' '

list top

$I$ is 0

1370 list +attr_val_sub_list

open csv file Attr_val_fuzzy for writing .

write csv file heading CollarID', 'code', 'Attr_val', 'cleaned_text', 'Fuzzy_wuzzy', 'Score'

1375 Convert 1ist Var.Attr_val_Dic to 1ist of 1ist Attr_val_Dic_new

For each element Attr_val_Dic_ele in Attr_val_Dic_new

cleaned_text_1= cal1 clean_text user defined function with attribute_value

cleaned_text_1=ca11 tokenize_and_lemma python function with cleaned text

cleaned_text_1

1380

cleaned_text=join each word of cleaned_text_1 with space as one string.

words is replace slashes by space using re pattern, strip leading and trailing spaces.

words is strip $\backslash n \backslash r$ and split on space.

for each element Litho_dico_ele in Var.Litho_dico

litho_words is Litho_dico_ele with lower case, rstrip $\backslash n \backslash r$, replace (or) by space and split on space

scores $=$ cal1 python process.extract with arguments cleaned_text, 1itho_words, scorer=fuzz.token_set_ratio

for sc in each scores

if $(\mathrm{sc}[1]>$ bestmatch $)$ : \#better than previous best match

1390

bestmatch $=\mathrm{sc}[1]$

best 1 itho= 1 itho_words [0]

top. append ( $[\mathrm{sc}[0], \mathrm{sc}[1]])$

if $(\mathrm{sc}[0]==$ words[last] $)$ : \#bonus for being last word in phrase

bestmatch=bestmatch*1.01

1395

elif (sc[1]==bestmatch): \#equal to previous best match

if $(\mathrm{sc}[0]==$ words[last] $)$ : \#bonus for being last word in phrase

best 1 itho=1itho_words [0]

bestmatch=bestmatch*1.01

1400

e1se:

if bestmatch $>80$ :

top. append ( $[\mathrm{sc}[0], \mathrm{sc}[1]])$

write bestlitho and bestmatch along with required data to csv file

clear top

CET_Litho as ' '

1405

Bestmatch as -1

e1se

Best 1 itho as ' '

write 'other' as bestlitho with bestmatch along with required data to csv file

clear top

1410

CET_Litho as ' '

Bestmatch as -1

Bestlitho as '"

\section{References}


1415 Amorin, R.: Application of Minimum Curvature method to Well-path Calculations, 2009.

Anand, R. R., and Butt, C. R. M.: A guide for mineral exploration through the regolith in the Yilgarn Craton, Western Australia, Australian Journal of Earth Sciences, 57, 1015-1114, Pii 929860728

10.1080/08120099.2010.522823, 2010.

Arabjamaloei, R., Edalatkha, S., Jamshidi, E., Nabaei, M., Beidokhti, M., and Azad, M.: Exact Lithologic Boundary Detection

1420 Based on Wavelet Transform Analysis and Real-Time Investigation of Facies Discontinuities Using Drilling Data, Petroleum Science and Technology, 29, 569-578, Pii 933125287

10.1080/10916460903419206, 2011.

Barley, M. E., Brown, S. J. A., Krapez, B., and Kositcin, N.: Physical volcanology and geochemistry of a Late Archaean volcanic arc: Kurnalpi and Gindalbie Terranes, Eastern Goldfields Superterrane, Western Australia, Precambrian Research,

1425 161, 53-76, 10.1016/j.precamres.2007.06.019, 2008.

Chace, F. M.: Abbreviations in field and mine geological mapping, Economic Geology, 51, 712-723, 1956.

Cockbain, A. E.: Regolith geology of the Yilgarn Craton - Introduction, Australian Journal of Earth Sciences, 49, 1-1, DOI 10.1046/j.1440-0952.2002.00913.x, 2002.

Cohen, A.: FuzzyWuzzy: Fuzzy string matching in python, ChairNerd Blog, 22, 2011.

1430 Culshaw, M. G.: From concept towards reality: developing the attributed 3D geological model of the shallow subsurface, Quarterly Journal of Engineering Geology and Hydrogeology, 38, 231-+, Doi 10.1144/1470-9236/04-072, 2005.

Eggleton, R. A.: The regolith glossary, Cooperative Centre for Landscape Evolution and Mineral Exploration, National Capital Printing: Canberra, 2001.

Elizabeth Griffin, R.: When are Old Data New Data?, GeoResJ, 6, 92-97, 10.1016/j.grj.2015.02.004, 2015.

1435 Emelyanova, I., Pervukhina, M., Clennell, M., and Dyt, C.: Unsupervised identification of electrofacies employing machine learning, 2017.

Erkan, G., and Radev, D. R.: LexRank: Graph-based lexical centrality as salience in text summarization, Journal of Artificial Intelligence Research, 22, 457-479, DOI 10.1613/jair.1523, 2004.

Fuentes, I., Padarian, J., Iwanaga, T., and Vervoort, R. W.: 3D lithological mapping of borehole descriptions using word

1440 embeddings, Computers \& Geosciences, 141, ARTN 104516

10.1016/j.cageo.2020.104516, 2020.

Gillespie, M., and Styles, M.: BGS rock classification scheme, Volume 1. Classification of igneous rocks, 1999.

Groves, D. I., Goldfarb, R. J., Knox-Robinson, C. M., Ojala, J., Gardoll, S., Yun, G. Y., and Holyland, P.: Late-kinematic timing of orogenic gold deposits and significance for computer-based exploration techniques with emphasis on the Yilgarn

1445 Block, Western Australia, Ore Geology Reviews, 17, 1-38, Doi 10.1016/S0169-1368(00)00002-0, 2000.

Hall, M., and Keppie, F.: Striplog: new open source software for handling and analysing discontinuous and qualitative data, 2016.

Hallsworth, C. R., and Knox, R.: BGS rock classification scheme. Volume 3, classification of sediments and sedimentary rocks, 1999.

1450 Higgins, R. F., and Mehta, S.: SeatGeek, 2018.

Hill, E. J., Robertson, J., and Uvarova, Y.: Multiscale hierarchical domaining and compression of drill hole data, Computers \& Geosciences, 79, 47-57, 10.1016/j.cageo.2015.03.005, 2015.

Hill, E. J., Pearce, M. A., and Stromberg, J. M.: Improving Automated Geological Logging of Drill Holes by Incorporating Multiscale Spatial Methods, Mathematical Geosciences, 1-33, 10.1007/s11004-020-09859-0, 2020.

1455 Jallan, Y., Brogan, E., Ashuri, B., and Clevenger, C. M.: Application of Natural Language Processing and Text Mining to Identify Patterns in Construction-Defect Litigation Cases, Journal of Legal Affairs and Dispute Resolution in Engineering and Construction, 11, Unsp 04519024

10.1061/(Asce)La.1943-4170.0000308, 2019.

Kumari, S., Mohan, A., and Saberwal, G.: Hidden duplicates: 10s or 100s of Indian trials, registered with ClinicalTrials.gov,

1460 have not been registered in India, as required by law, PLoS One, 15, e0234925, 10.1371/journal.pone.0234925, 2020.

Lark, R. M., Thorpe, S., Kessler, H., and Mathers, S. J.: Interpretative modelling of a geological cross section from boreholes: sources of uncertainty and their quantification, Solid Earth, 5, 1189-1203, 10.5194/se-5-1189-2014, 2014.

Le Vaillant, M., Hill, J., and Barnes, S. J.: Simplifying drill-hole domains for 3D geochemical modelling: An example from the Kevitsa Ni-Cu-(PGE) deposit, Ore Geology Reviews, 90, 388-398, 10.1016/j.oregeorev.2017.05.020, 2017.

1465 Lin, C.-Y., and Hovy, E.: Automatic evaluation of summaries using n-gram co-occurrence statistics, Proceedings of the 2003 Human Language Technology Conference of the North American Chapter of the Association for Computational Linguistics, 2003, 150-157,

Lindsay, M.: Geological Interpretation of Geophysics Support from Machine Learning of Drillcore, 2019.

Liu, K., Hogan, W. R., and Crowley, R. S.: Natural Language Processing methods and systems for biomedical ontology

1470 learning, J Biomed Inform, 44, 163-179, 10.1016/j.jbi.2010.07.006, 2011.

Liu, T., and Guo, J.: Text similarity computing based on standard deviation, International Conference on Intelligent Computing, 2005, 456-464,

Loper, E., and Bird, S.: NLTK: the natural language toolkit, arXiv preprint cs/0205028, 2002.

McKinney, W.: pandas: a foundational Python library for data analysis and statistics, Python for High Performance and

1475 Scientific Computing, 14, 2011

McMillan, A., and Powell, J.: British Geological Survey Rock Classification Scheme: The Classification of Artificial (man made) Ground and Natural Superficial Deposits: Applications to Geological Maps and Datasets in the UK, British Geolgoical Survey Research Report RR/99/4, 1999. 
Miles, A., and Bechhofer, S.: SKOS simple knowledge organization system reference, W3C recommendation, 18 , W3C, 2009.

1480 Müller, T., Cotterell, R., Fraser, A., and Schütze, H.: Joint lemmatization and morphological tagging with lemming, Proceedings of the 2015 Conference on Empirical Methods in Natural Language Processing, 2015, 2268-2274,

Myers, J.: Precambrian Tectonic History of the West Australian Craton and Adjacent Orogens, Annu Rev Earth P1 Sc, 21, 453485, 10.1146/annurev.ea.21.050193.002321, 1993.

Okuda, T., Tanaka, E., and Kasai, T.: A method for the correction of garbled words based on the Levenshtein metric, IEEE

1485 Transactions on Computers, 100, 172-178, 1976

Otter, D. W., Medina, J. R., and Kalita, J. K.: A Survey of the Usages of Deep Learning for Natural Language Processing, IEEE Trans Neural Netw Learn Syst, 10.1109/TNNLS.2020.2979670, 2020.

Padarian, J., and Fuentes, I.: Word embeddings for application in geosciences: development, evaluation and examples of soilrelated concepts, 10.5194/soil-2018-44, 2019.

1490 Park, S. H., Ryu, K. H., and Gilbert, D.: Fast similarity search for protein 3D structures using topological pattern matching based on spatial relations, Int J Neural Syst, 15, 287-296, 10.1142/S0129065705000244, 2005.

Qiu, Q., Xie, Z., Wu, L., and Tao, L.: Dictionary-Based Automated Information Extraction From Geological Documents Using a Deep Learning Algorithm, Earth and Space Science, 7, 10.1029/2019ea000993, 2020.

Ralph, J.: Mindat. org-the mineral database, Mindat, Surrey, England, 2004.

1495 Raymond, O., Duclaux, G., Boisvert, E., Cipolloni, C., Cox, S., Laxton, J., Letourneau, F., Richard, S., Ritchie, A., and Sen, M.: GeoSciML v3. 0-a significant upgrade of the CGI-IUGS geoscience data model, EGUGA, $2711,2012$.

Recasens, M., Danescu-Niculescu-Mizil, C., and Jurafsky, D.: Linguistic models for analyzing and detecting biased language, Proceedings of the 51st Annual Meeting of the Association for Computational Linguistics (Volume 1: Long Papers), 2013, 1650-1659,

1500 Richard, S. M., Boisvert, E., Brodaric, B., Cox, S., and Duffy, T.: GeoSciML-a GML application for geoscience information interchange, Philadelphia Annual Meeting, 2007, 47-59,

Riganti, A., Farrell, T. R., Ellis, M. J., Irimies, F., Strickland, C. D., Martin, S. K., and Wallace, D. J.: 125 years of legacy data at the Geological Survey of Western Australia: Capture and delivery, GeoResJ, 6, 175-194, 10.1016/j.grj.2015.02.015, 2015. Rivera-Quiroz, F. A., and Miller, J.: Extracting Data from Legacy Taxonomic Literature: Applications for planning field work,

1505 Biodiversity Information Science and Standards, 3, 10.3897/biss.3.37082, 2019.

Robertson, S.: BGS rock classification scheme. Volume 2, Classification of metamorphic rocks, 1999.

Rosenbaum, M. S., McMillan, A. A., Powell, J. H., Cooper, A. H., Culshaw, M. G., and Northmore, K. J.: Classification of artificial (man-made) ground, Engineering Geology, 69, 399-409, 10.1016/S0013-7952(02)00282-X, 2003.

Ross, P. S., Bourke, A., and Fresia, B.: A multi-sensor logger for rock cores: Methodology and preliminary results from the

1510 Matagami mining camp, Canada, Ore Geology Reviews, 53, 93-111, 10.1016/j.oregeorev.2013.01.002, 2013.

Rothwell, R. G., and Rack, F. R.: New techniques in sediment core analysis: an introduction, New Techniques in Sediment Core Analysis, 267, 1-29, Doi 10.1144/Gsl.Sp.2006.267.01.01, 2006.

Simons, B., Boisvert, E., Brodaric, B., Cox, S., Duffy, T. R., Johnson, B. R., Laxton, J. L., and Richard, S.: GeoSciML: enabling the exchange of geological map data, ASEG Extended Abstracts, 2006, 1-4, 2006.

1515 Smith, M. J., Keesstra, S., and Rose, J.: Use of legacy data in geomorphological research, GeoResJ, 6, 74-80, 10.1016/j.grj.2015.02.008, 2015.

Vearncombe, J., Conner, G., and Bright, S.: Value from legacy data, Transactions of the Institutions of Mining and Metallurgy Section B-Applied Earth Science, 125, 231-246, 10.1080/03717453.2016.1190442, 2016.

Vearncombe, J., Riganti, A., Isles, D., and Bright, S.: Data upcycling, Ore Geology Reviews, 89, 887-893,

1520 10.1016/j.oregeorev.2017.07.009, 2017.

Wang, C., and Ma, X.: Text Mining to Facilitate Domain Knowledge Discovery, in: Text Mining-Analysis, Programming and Application, IntechOpen, 2019.

Wilbur, W. J., and Sirotkin, K.: The Automatic Identification of Stop Words, Journal of Information Science, 18, 45-55, Doi 10.1177/016555159201800106, 1992.

1525 Zhou, C. Y., Ouyang, J. W., Ming, W. H., Zhang, G. H., Du, Z. C., and Liu, Z.: A Stratigraphic Prediction Method Based on Machine Learning, Appl Sci-Basel, 9, ARTN 3553 10.3390/app9173553, 2019.

Zhou, Q., Liu, H. H., Bodvarsson, G. S., and Oldenburg, C. M.: Flow and transport in unsaturated fractured rock: effects of multiscale heterogeneity of hydrogeologic properties, J Contam Hydrol, 60, 1-30, 10.1016/s0169-7722(02)00080-3, 2003.

1530 Zhu, G., Gao, M., Kong, F., and Li, K.: Application of Logging While Drilling Tool in Formation Boundary Detection and Geo-steering, Sensors (Basel), 19, 10.3390/s19122754, 2019. 